\title{
Differential Gene Expression and Hallmarks of Stemness in Epithelial Cells of the Developing Rat Epididymis
}

\section{Julie Dufresne}

Institut National de la Recherche Scientifique

Mary Gregory

Institut National de la Recherche Scientifique

Laurie Pinel

Institut National de la Recherche Scientifique

Daniel Cyr ( $\nabla$ daniel.cyr@inrs.ca )

Institut National de la Recherche Scientifique https://orcid.org/0000-0002-6566-783X

\section{Research Article}

Keywords: Epididymis, Cell Isolation, Genomics, CD49f, cell signaling, columnar cells

Posted Date: February 9th, 2022

DOI: https://doi.org/10.21203/rs.3.rs-1287069/v1

License: (c) (i) This work is licensed under a Creative Commons Attribution 4.0 International License. Read Full License 


\section{Abstract}

Epididymal development can be subdivided into three phases: undifferentiated, a period of expansion, and a period of differentiation. The objectives of this study were: (1) to assess gene expression profiles in epididymides; (2) predict signalling pathways and (3) develop a novel 3D cell culture method to assess the regulation of epididymal development in vitro. Microarray analyses indicate that the largest changes in differential gene expression occurred between the 7 to 18-day period, in which 1452 genes were differentially expressed; while 671 differentially expressed genes were noted between day 18 and 28, and there were 560 differentially expressed genes between days 28 and 60 . Multiple signalling pathways were predicted at different phases of development. Pathway associations indicated that in epididymides of 7 to 18-day old rats. there was a significant association of regulated genes implicated in stem cells, estrogens, thyroid hormones, and kidney development, while androgen- and estrogen-related pathways were enriched at other phases of development. Organoids were derived from CD49f+ columnar cells from 7-day old rats, while no organoids developed from CD49f- cells. Cells cultured in an epididymal basal cell organoid medium versus a commercial kidney differentiation medium supplemented with DHT revealed that irrespective of the culture medium, cells within differentiating organoids expressed p63, AQP9 and VATPase after 14 days of culture. The commercial kidney medium resulted in an increase in the number of organoids positive for p63, AQP9, and V-ATPase. Together, these data indicate that columnar cells represent an epididymal stem/progenitor cell population.

\section{Introduction}

The role of the epididymis in sperm maturation and the acquisition by sperm of both motility and the ability to fertilize has been well established (Elbashir, et al., 2021, Jones, et al., 2007, Robaire and Hinton, 2015). The luminal environment of the epididymis necessary for sperm maturation is created in part by modulation of $\mathrm{pH}$, secretion of sperm-binding proteins by the epididymis, and the presence of the bloodepididymis barrier, which regulates transcellular transport and receptor-mediated transport of selected molecules across the epithelium and their release into the lumen (Cornwall, 2009, Cyr, et al., 2007, Dube, et al., 2007, Dube and Cyr, 2012). As such, the development and differentiation of the epididymal epithelium represents a critical aspect of male fertility.

The regulation of the cellular differentiation of the epididymis remains poorly understood. Electron microscopy studies (Hermo, et al., 1992, Rodriguez, 2002, Sun and Flickinger, 1979) led to the suggestion that postnatal epididymal development could be subdivided into three distinct phases in rat: undifferentiated epithelium (birth to day 14), a period of expansion (days 14 to 44 ) and a period of differentiation (day 44 to adult). In the undifferentiated phase of epididymal development, the epithelium is comprised of small undifferentiated columnar cells (Rodriguez, 2002, Sun and Flickinger, 1979). These cells are believed to be the precursors to other cell types of the differentiated epithelium (Rodriguez, 2002, Sun and Flickinger, 1979). One of the first markers expressed in a subpopulation of columnar cells during early development (days 14- 21) is the transcription factor p63 (Gregory and Cyr, 2019, Hayashi, et al., 2004, Murashima, et al., 2015, Murashima, et al., 2011, Saito, et al., 2006). In the differentiated adult 
epithelium, p63 is expressed exclusively in the basal cells (Gregory and Cyr, 2019, Hayashi, Yoshinaga, Ohno, Ishii, Kamata and Yamada, 2004, Pinel, et al., 2019, Saito, Kawakami, Okada, Takazawa, Koga, Kageyama and Kihara, 2006). This would suggest that the expression of p63 in a subset of small columnar cells represents either basal cells or precursors of basal cells (Gregory and Cyr, 2019). During early postnatal development, these cells become associated with the basal region of the epithelium. Morphologically, principal cells become apparent at day 28, while clear cells are evident at day 35 (Hermo, Barin and Robaire, 1992, Rodriguez, 2002).

Studies by Mandon et al (Mandon, et al., 2015a) suggested that basal cells represent an adult stem cell population. Mou (Mou, et al., 2016) showed that subcutaneous transplants of KRT5+ (cytokeratin 5positive) murine epididymal basal cells in nude mice resulted in organoids whose cells had differentiated into principal cells. Furthermore, Pinel and Cyr (Pinel, 2020) showed that CD49f (integrin-alpha6)-positive rat basal cells have the ability to self-renew, form epididymal organoids, and can differentiate in vitro, further supporting the notion that these are stem cells. Since basal cells are derived from undifferentiated small columnar cells early in postnatal development, it stands to reason that the undifferentiated cells are also stem cells and that $163^{+}$basal cells likely represent a slowly- dividing or quiescent stem cell population. This has been shown in other tissues such as the trachea, for example (Kim, et al., 2012, Rock, et al., 2010, Roomans, 2010). While the timing of the appearance of different cell types in the epididymis is well-established, there is little information on the signaling pathways regulating the differentiation of the epithelium.

A large number of studies have examined gene expression during postnatal development in rodent animal models; however, few studies have attempted to predict signaling pathways associated with the phases of epididymal differentiation. Turner et al (Turner, et al., 2007) showed that segment-specific gene expression in the adult mouse was lost following efferent duct ligation, indicating an influence of testicular factors. Hedgehog signaling and primary cilia of principal and basal cells appear to play a role in the early development of the epididymis (Girardet, et al., 2020). Several studies have shown a role for pMAPK1/3 signaling in cell proliferation and the regulation of PTEN and SRC (Xu, et al., 2018, Xu, et al., 2014, Xu, et al., 2010), as well as the role of HNF (Browne, et al., 2019). Both androgens and estrogens have been shown to play a role in epididymal development and cellular differentiation (Breton, et al., 2016, Hejmej and Bilinska, 2018, Hess, et al., 2021, Ribeiro, et al., 2017, Sipila and Bjorkgren, 2016).

Nonetheless, we have a very limited understanding of the pathways that are activated at each stage of epididymal development. Furthermore, the characterization of undifferentiated epididymal columnar cells, as well as the signaling pathways implicated in the differentiation of these cells into basal and principal cells, remain to be fully elucidated. The objectives of the present study were to assess gene expression by transcriptomic analyses in the epididymis at different stages of development, using a genomics approach; to predict signaling pathways that may play a role in epididymal cellular differentiation, and to develop a novel in vitro model using CD49f+ columnar cells cultured under 3D conditions.

\section{Material And Methods}




\section{Animals and tissues collection}

Male Sprague-Dawley rats (7-, 18-, 28- and 60-days of age) were purchased from Charles River Laboratories, Inc. (Fairfield, New Jersey). Rats were acclimated for one week under constant photoperiod (12h light: $12 \mathrm{~h}$ dark), and received food and water ad libitum. At the time of sampling, rats were anesthetized with $\mathrm{CO}_{2}$ and killed by cervical dislocation or decapitation. Epididymides were dissected from rats under aseptic conditions and either frozen in liquid nitrogen and stored at $-86^{\circ} \mathrm{C}$ or placed in Dulbecco Modified Eagles Medium (DMEM)/HAM F12 culture media containing penicillin $(50 \mathrm{U} / \mathrm{mL}$ ) and streptomycin $(50 \mu \mathrm{g} / \mathrm{mL})$ (Sigma-Aldrich, Oakville, ON). All the animal protocols used in this study were approved by the university animal care committee.

\section{Microarray Processing}

Total cellular RNA was isolated from pools of whole epididymides of 7- $(n=3), 18-(n=4), 28-(n=4)$ and 60day $(n=3)$ old rats using the Nucleospin RNA Plus Kit (Macherey-Nagel, Allentown, PA) according to the manufacturer's instructions. To remove all traces of contaminating genomic DNA (gDNA), RNA was then DNase-treated (RNase-Free DNase set; Qiagen) and purified using the RNeasy Mini Kit (Qiagen, Redwood City, CA). The RNA concentration was determined using a NanoDrop One spectrophotometer (NanoDrop Technologies, Wilmington, DE) and PCR was performed to verify the absence of gDNA. Gene expression profiling was done using a rat oligonucleotide microarray (Affymetrix GeneChip ${ }^{\circledR}$ Rat Gene 2.0 ST array; Thermo Fisher Scientific, Ottawa, ON), containing 28407 RefSeq transcripts. Hybridizations were done by Genome Québec's Innovation Centre (McGill University, Montréal, QC). RNA quality (RNA integrity number higher than 9) was assessed using an Agilent 2100 Bioanalyzer (Agilent Technologies, Santa Clara, CA). The GeneChip WT Plus Reagent kit (Thermo Fisher Scientific) was used to reverse transcribe the RNA samples into CDNA, amplify them by in vitro transcription and convert them into biotin-labeled sensestranded CDNA. The CDNA was then hybridized to the arrays, stained with a streptavidin-phycoerythrin conjugate and the arrays were scanned using a GeneChip Scanner $30007 \mathrm{G}$ (Thermo Fisher Scientific).

\section{Microarray Analysis}

The relative expression level of each transcript was obtained from three or four separate pools of tissues for each age from which RNA was isolated. Raw data were corrected for background, quantilenormalized and summarized using the RMA (Robust Multi-Chip Analysis) algorithm of the Transcriptome Analysis Console (TAC) Software 4.0.1 (Thermo Fisher Scientific). Analyses were done according to MIAME (minimum information about a microarray experiment) standards (Brazma, et al., 2001). Only genes showing a FDR adjusted $p$-value $<0.05$ and an overall FDR F-test $<0.05$ were considered for data analysis. Differential expression analysis used eBayes ANOVA method of the LIMMA (Linear Models for Microarray data) package implemented in the TAC software.

Principal component analysis (PCA), hierarchical clustering, and volcano plots were performed with the TAC software. Protein class identification of highly regulated gene (18 vs 7-day comparison) was done using the PANTHER Knowledgebase (Mi, et al., 2021). Differentially expressed genes (1.5-fold change) 
were uploaded to 3 different software programs to analyze the enriched KEGG (Kyoto Encyclopedia of Genes and Genomes) pathways for different age comparisons (d7 vs d60, d18 vs d7, d28 vs d18 and d60 vs d28): the DAVID Bioinformatics Resources software (version 6.8; Database for Annotation, Visualization, and Integrated Discovery; Laboratory of Human Retrovirology and Immunoinformatics (Huang da, et al., 2009a, Huang da, et al., 2009b); g:Profiler (version e101_eg48_p14_d87511f) (Raudvere, et al., 2019); and String (version 11.0) (Szklarczyk, et al., 2019).

In DAVID, calculations of enrichment scores were based on Expression Analysis Systematic Explorer

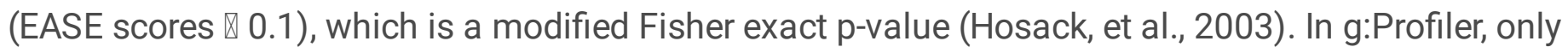
annotated genes were selected. Pathways were identified when consistently enriched using these three software programs and with a FDR p-value corrected for multiple testing using the Benjamini-Hochberg procedure and applying a significance threshold of 0.05 .

The enrichment of GO annotations in the Biological Processes and Clustering analyses of non-redundant terms were analyzed with Metascape (Zhou, et al., 2019) for differentially expressed genes with a 2-fold change in expression ( $d 18$ vs d7, d28 vs d18 and d60 vs d28). Heatmaps were generated using the Heatmapper software (Babicki, et al., 2016) without selecting any cutoff in gene expression levels or statistical tests.

Membership search of different terms (stem cell, androgen, estrogen, cell junction, frizzled, immune system, epidermal growth factor, thyroid hormone, kidney differentiation) using Metascape was applied to the following ontologies: GO Biological Processes, KEGG Pathway, Reactome Gene Sets, WikiPathways. Binary $1 / 0$ results for each gene in the input list (differentially expressed genes with a 2fold change in expression ( $d 18$ vs d7, d28 vs d18 and d60 vs d28) were summarized. The number of genes in the input gene list (percentage relative to the background) associated with the membership was compared to the number of genes in the background associated with the membership, relative to the same background (whole genome) to generate a p-value.

\section{Epididymal Organoids/Isolation of CD49f-positive cells}

Epididymal organoids were derived from total cells or from Cd49f-positive cells isolated from epididymides of 7-day old rats, following a protocol previously described for isolating basal cells from adult (48-day old) rats and establishing basal cell organoids (Mandon, et al., 2015b, Pinel, 2020). Briefly, 7-day old male rats were euthanized; epididymides were removed under aseptic conditions and placed immediately into pre-warmed DMEM containing antibiotics (penicillin $(50 \mathrm{U} / \mathrm{mL}$ ) and streptomycin $(50 \mu \mathrm{g} / \mathrm{mL})$ (Sigma-Aldrich)). Epididymides were trimmed from surrounding connective tissue and fat and digested in a $37^{\circ} \mathrm{C}$ water bath with gentle agitation in the same medium containing collagenase (type I, 2 $\mathrm{mg} / \mathrm{mL}$; Gibco, Thermo Fisher Scientific). Two rounds of digestion with fresh medium were performed for $50 \mathrm{~min}$ each, followed by a final digestion period of $10 \mathrm{~min}$. After allowing the digested fragments to sediment to the bottom of the flask, most of the medium was removed and replaced with a Trypsin-EDTA solution, and incubated for $10 \mathrm{~min}$ at $37^{\circ} \mathrm{C}$ with gentle agitation. Addition of FBS stopped the reaction 
and the suspension was then transferred to sterile 50 -ml centrifuge tubes and centrifuged for $5 \mathrm{~min}$ at $100 \mathrm{~g}$. The supernatant was removed, discarded, and the cell pellet resuspended in fresh cold DMEM medium containing antibiotics. This suspension was then sequentially filtered through 100,70 , and 40 $\mu \mathrm{m}$ nylon filters, followed by a viability test and cell counts using Trypan blue. For total cells organoid cultures, the suspension was cultured in medium/Matrigel drops as described below.

The suspension was again centrifuged at $300 \mathrm{~g}, 4^{\circ} \mathrm{C}$ for 5 min and the resulting supernatant carefully removed. The pellet was placed on ice and incubated with cold MACS buffer (PBS pH 7.2, 25 mM EDTA, $5 \% \mathrm{BSA})$ containing antibody ( $1 \mu \mathrm{g}$ per $\left.1 \times 10^{6} \mathrm{cells}\right)$. Cells were incubated with MACS buffer and anti-rat CD49f antibody (integrin-a6; BioRad/Serotec) for $20 \mathrm{~min}$ on ice, followed by three centrifugations (10 min, $300 \mathrm{~g}, 4^{\circ} \mathrm{C}$ ) and washes. Anti-mouse magnetic beads (Miltenyi Biotec, San Diego, CA) were then added and incubated with the cellular suspension for $15 \mathrm{~min}$ on ice. An additional series of three centrifugations and washes were performed, followed by magnetic separation of cells, according to the manufacturer's instructions (Miltenyi Biotec). The cellular suspension containing cells bound to magnetic beads-antibody complexes were then passed through MS separation columns (Miltenyi Biotec) in the presence (negative fraction, Cd49f) or absence (positive fraction, CD49f+) of a magnetic field. Aliquots of cells from each fraction were mixed with Trypan blue and cell counts of all fractions were performed in duplicate. Cellular suspensions were then incubated with appropriate volumes of Advanced DMEM/Matrigel (1:1 mixture) on ice. Drops of cell suspensions/Matrigel (Corning, Glendale, AZ; 20,000 cells per drop) were placed on pre-warmed 24-well Cell+ plates (Sarstedt, Montreal, QC) or 8-chamber glass slides (Labtek, ThermoFisher), allowed to set upside down for $30 \mathrm{~min}$ in a $37^{\circ} \mathrm{C}$ incubator, and then covered with warmed medium containing appropriate supplements. The organoid cultures were grown in a $32^{\circ} \mathrm{C}, 5 \% \mathrm{CO}_{2}$ incubator and $50 \%$ of the medium was replaced every 2 days until the end of the experiment.

\section{Expansion and Differentiation of Organoids}

Organoids were grown in medium containing appropriate supplements for up to 14 days. For the initial period ( 6 days) of expansion, epididymal organoid medium was composed of Advanced DMEM/F12, heparin $(4 \mu \mathrm{g} / \mathrm{ml})$, Glutamax (1X), HEPES (10 mM) and EGF (10 ng/ml; ThermoFisher); Tocopherol (200ng/ml), A8301 (250 nM), N-acetylcysteine (1.25 mM), cAMP (10 ng/ml), hydrocortisone $(80 \mathrm{ng} / \mathrm{ml})$, and DHT (10 nM; Sigma-Aldrich), and bFGF (10 ng/ml; Sino Biological, Wayne, PA). The medium was sterilized through a $0.22 \mu \mathrm{m}$ filter prior to the addition of $\mathrm{DHT}$, and stored at $4^{\circ} \mathrm{C}$. For differentiation, the following components were added to the medium: Cholera toxin ( $100 \mathrm{ng} / \mathrm{ml}$; Sigma Aldrich), the ROCK inhibitor Y27632 $(10 \mu \mathrm{M})$, R-Spondin (500 ng/ml), and Noggin (100 ng/ml; Peprotech, Cranbury, NJ). Medium (50\%) was replaced every 2 days until the end of the experiment.

In a series of parallel experiments, organoids derived from CD49f+ cells were cultured in growth medium, as described above, for 6 days. On day 6 , this growth medium was replaced with medium plus supplements for differentiation, as described above, or with commercially-available STEMdiff basal kidney medium, designed for kidney organoids, supplemented with STEMdiff SG supplements (StemCell Technologies, Vancouver, BC). After 36-40 hrs, this medium was replaced with STEMdiff basal kidney 
medium plus STEMdiff DM supplements, and organoids were cultured for an additional week until day 14 of the experiment. Multiple wells of organoids were grown under both types of media, and experiments were repeated twice.

\section{Quantitation of Organoid Size}

In order to assess the growth of specific organoids over time, a Cytation 5 Imaging Multi-Mode Reader (Biotek, Winooski, VT) was used. Beginning on day 1, randomly selected defined coordinates of the organoids in multiple wells were monitored and tracked throughout the period of culture (14 days). A minimum of 4 fields per drop, and 4 drops per plate, were viewed and photographed at multiple time points throughout the experiment.

To quantify size and numbers of organoids, as well as number of organoids stained with a cell-specific marker, organoids were stained with fluorescent antibodies and counted in each chamber of a Labtek slide (ThermoFisher) at the end of each experiment (day 14). Organoids smaller than $40 \mu \mathrm{m}$ in diameter were not included in the counts. Organoids equal to or greater than $40 \mu \mathrm{m}$ in diameter were classified into two size categories: $40-80 \mu \mathrm{m}$, and greater than $80 \mu \mathrm{m}$. A minimum of 3 chambers for each cell-specific marker were counted, and experiments were performed at least twice.

\section{Immunofluorescence}

Immunofluorescent staining of organoids using cell-specific markers was performed at days 7 and 14 of each experiment, according to standard protocols. Briefly, medium was gently removed by aspiration from each well, and organoid culture drops rinsed with PBS. They were then fixed with ice-cold methanol for $20 \mathrm{~min}$ at $-20^{\circ} \mathrm{C}$, or $4 \%$ paraformaldehyde (PFA) for $15 \mathrm{~min}$ at room temperature. Organoids were washed three times with TBS (Tris-buffered saline) containing 0.3M glycine (ThermoFisher) for $10 \mathrm{~min}$, permeabilized with $0.3 \%$ Triton-X-100 (ThermoFisher) in PBS for 15 min and washed three times with TBS-Tween $(0.1 \%)$ in $0.3 \mathrm{M}$ glycine (TBS-T-glycine). All subsequent washes were done using TBS-Tglycine. Blocking was performed with a solution containing $5 \%$ normal donkey serum (Jackson Immunoresearch Laboratories, West Grove, PA) and 3\% BSA in TBS-T-glycine for 90 min. Immunolabelling was done using different primary antibodies (Supplemental Table I) diluted in blocking solution and incubated overnight at $4^{\circ} \mathrm{C}$. Organoids were then washed in TBS-T-glycine and incubated at room temperature for 90 min with a donkey anti-rabbit Rhodamine Red-conjugated or a donkey anti-mouse AF488 conjugated secondary antibody $(3.1 \mu \mathrm{g} / \mathrm{ml}$; Jackson Immunoresearch Laboratories) containing Hoechst dye $(1.0 \mu \mathrm{g} / \mathrm{ml}$; Biotium, Scarborough, ON). Following incubation with the secondary antibody, slides were washed again three times with TBS-T-glycine, and a final wash in TBS only. Slides were mounted in Fluoromount (Southern Biotech, Birmingham, AL). Organoids incubated without primary antibody were used as a negative control. Immunofluorescence was examined under a Zeiss LSM 780 confocal microscope. Images were processed using the Zen software (Oberkochen, Germany).

\section{Real Time Reverse Transcription Polymerase Chain Reaction}


Real-time RT-PCR assays were performed on rat tissue total RNA to validate the microarray analyses and on total RNA extracted from organoids as described previously (Mandon, Hermo and Cyr, 2015a). Total cellular RNA was isolated from organoid cultures as follows: medium was removed from each well and rinsed gently with PBS. Dispase (1 mg/ml, Gibco, ThermoFisher) was added to each well and incubated at $37^{\circ} \mathrm{C}$ until the Matrigel was dissociated. The resulting suspensions were collected and additional dispase was used to rinse all of the wells and collect any residual cells. This was followed by a series of three PBS washes and centrifugation (300 g) steps. The resulting cell pellets were resuspended in RNA extraction lysis buffer (Macherey-Nagel) and stored at $-80^{\circ} \mathrm{C}$. Total RNA was extracted using the NucleoSpin RNA Plus kit (Macherey-Nagel) following the manufacturer's instructions. Concentration and purity of the RNA was assessed using a NanoDrop (ThermoFisher Scientific).

An aliquot of RNA (250 ng from tissues; or 20 to $50 \mathrm{ng}$ from organoids) was reverse transcribed using qScript ${ }^{\circledR}$ cDNA SuperMix (Quanta BioSciences, Beverly, MA) and real time PCR was performed using the PerfeCTa TM SYBR Green SuperMix (Quanta Biosciences). Real time-PCR was done using a Rotor-Gene RG3000 (Corbett Life Science, Mortlake, NSW, Australia). Primers were designed using Primer Blast software (National Center for Biotechnology Information, NIH, Bethesda MD) and Oligo Primer Analyses Software (Molecular Biology Insights, Cascade, CO). The sequences of the primers are listed in Supplemental Table II. Standard curves using appropriate cDNA were created for all genes examined and used to calculate relative expression levels. Relative mRNA levels of target genes of interest were normalized to the Atp5pb mRNA or 18S rRNA, for microarray validation or organoid experiments, respectively. All samples were done in triplicate.

\section{Flow Cytometry}

Frozen samples of total epididymal cells from 10-day old rats were thawed on ice and gently resuspended in DMEM medium containing 10\% FBS. Cells were centrifuged (300g; $7 \mathrm{~min})$. The supernatant was discarded and the pelleted cells were suspended in FACS buffer for counting (0.1\% BSA in 1X PBS). Cells were distributed as 700000 cell aliquots into $1.5 \mathrm{ml}$ tubes, centrifuged (300g; $7 \mathrm{~min}$ ) and resuspended in blocking buffer (FACS buffer containing 2\% BSA and 10\% normal donkey serum). Cells were incubated on ice for $30 \mathrm{~min}$. A mouse monoclonal anti-rat CD49f antibody conjugated with

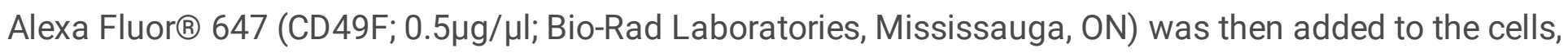
and the mixture was incubated on ice for $1 \mathrm{~h}$ in the dark. Cells were washed two times with 1 ml of FACS buffer and resuspended in 350 ul of FACS buffer containing Hoechst dye $(0.05 \mu \mathrm{g} / \mathrm{ml}$; Biotium) and incubated on ice for 10 mins. Cells were then washed once with $1 \mathrm{ml}$ of FACS buffer, resuspended in 350 ul of FACS buffer and transferred to FACS tubes. Flow cytometric analyses were done using an LSR Fortessa and Cell Quest Pro software (BD Biosciences, Franklin Lakes, NJ).

\section{Statistics}

Each experiment used in organoid culture and analyses contained a minimum of three replicates and was repeated at least twice unless otherwise indicated. Statistical analyses were done using SigmaPlot 
(version 12.5, USA). Values are presented as mean \pm SEM. Statistical significance was calculated using a Student's t-test and/or Mann-Whitney U-test, as applicable; $p$-values $\leq 0.01$ were considered significant.

\section{Results}

\section{Gene expression profiling of epididymides from 7, 18, 28 and 60-day old rats}

In order to identify specific genes associated with epididymal columnar cells, microarray analyses were used to compare gene expression profiles in epididymides of 7-, 18-, 28- and 60-day old rats. Rat oligonucleotide microarrays containing 28407 RefSeq transcripts were used to assess gene expression levels. Box plot analyses of the arrays indicated that the overall signal between arrays was similar and that the data from the different arrays could be normalized to assess gene expression in epididymis from rats of different ages (Fig. 1A). Three-dimensional component analyses indicated that the expression data within an age group was similar between biological replicates, but that there existed a marked difference in gene expression between different ages., indicating that the gene expression profiles were different between epididymides of different ages, (Fig. 1B). Unsupervised hierarchical clustering using the Euclidean distance between objects and the complete linkage method between clusters indicated specific changes in gene expression at different age-dependent phases of epididymal development, with clearly identifiable genes that either increased or decreased as a function of age (Fig. 1C). Volcano plots comparing gene expression between consecutive sampling ages indicated both significantly increased and decreased gene expression patterns (Fig. 2A-C). The largest change occurred between the 7 to 18-day period, in which a total of 1452 differentially expressed genes (2-fold change) were observed, while 671 differentially expressed genes were noted between day 18 and 28, and 560 differentially expressed genes between days 28 and 60 . In the day 18 to day 7 comparison, 1084 genes were shown to be specifically modulated, whereas 297 and 331 transcripts were specifically regulated in the 28-vs 18-day and 60-vs 28-day analyses, respectively (Fig. 2D). The number of upregulated genes by a 2-, 3-, 4-, or 5 -fold change was always higher than the number of downregulated genes in every comparison (18 to $7 ; 28$ to $18 ; 60$ to 28-day comparisons), except for the 2 -fold change- regulated genes when d18 was compared to day 7 (787 downregulated genes; 665 upregulated genes (Fig. 2E). Remarkably, of the 1452 differentially expressed genes between days 7 and 18, 107 genes were upregulated by a factor of 5 -fold or more. The 40 coding transcripts showing the highest degrees of differential expression are presented in Supplemental Table III. Grouping of the 107 upregulated genes by protein class using the PANTHER web resource for classification indicated that the majority of transcripts showing an increased expression are associated with defence/immunity, enzymes, transporters and channels, protease inhibitors, and carrier and scaffold proteins (Fig. 2F).

Gene expression profiles between days 18 and 28 indicated 344 upregulated and 327 downregulated genes. Of these, there were 103 genes that were highly upregulated by a factor of at least 4-fold, with 71 genes upregulated by a factor of at least 5-fold. Only 16 genes were downregulated by a factor of at least 
4-fold, and 8 of them by a factor of at least 5 -fold. (Fig. 2E). Highly regulated coding transcripts are presented in Supplemental Table IV.

Comparison of the expression profiles between 28 and 60 days revealed 406 upregulated genes, while 154 genes were downregulated. Of these, 82 were highly upregulated with increases of 4 - to 5 -fold, while only 11 genes were highly downregulated (Fig. 2E). Coding transcripts of highly regulated genes are presented in Supplemental Table V. Upregulated genes during the 28 to 60 day transition included defensins (Ribeiro, et al., 2016), lipocalins (Fouchecourt, et al., 2003) and a transcript encoding a protein of the specialized mitochondria present in the midpiece of the sperm flagella, SMCP (sperm mitochondria-associated cysteine-rich protein) (Kleene, et al., 1994).

\section{Enriched Genes Grouped According to Their Biological Processes}

Genes that were differentially expressed between subsequent sampling ages were grouped according to their biological processes and clustered using Metascape (Zhou, Zhou, Pache, Chang, Khodabakhshi, Tanaseichuk, Benner and Chanda, 2019). While the data show that multiple processes are activated or repressed between ages, it is interesting to note that several highly significant biological processes were consistently identified between different ages, including regulation of biological processes, cell metabolism, and various immune-related functions. Likewise, clusters of genes such as defensins and defensin-related genes were present at all ages. It is noteworthy that comparisons in gene expression profiles between days 18 and 7 indicated clusters of genes implicated in urogenital, vascular, skeletal, and skin development, as well as in renal system processes, suggestive of common genes implicated in development (Fig. 3).

\section{Genes Implicated in Cell-Cell Interaction}

Cellular junctions play an essential role in development and the formation of the blood-epididymis barrier (Cyr, et al., 2018, Dube, Chan, Hermo and Cyr, 2007, Dube and Cyr, 2012). Dynamic changes in the expression of cadherins (adherens junctions), tight junction proteins (claudins, occludin and tight junction proteins) and connexins (gap junctions) have been previously shown to be regulated in epididymal development. While specific genes implicated in these functions vary with development, it is noteworthy that several genes implicated in cell adhesion are highly expressed in epididymides of day 7 rats (CDH1, $\mathrm{CDH} 3, \mathrm{CDH} 5, \mathrm{CDH} 11, \mathrm{CDH} 13$, and $\mathrm{CDH} 16$ ), and remain elevated until day 60 (Fig. 4A). Interestingly, CLDN4, CLDN23, occludin, TJP2 and TJP3 show an increased expression at day 18, when the tight junctions of the blood-epididymis barrier become impermeable. This also coincides with an increase in gap junction proteins GJB5 (Cx31.1), and GJB3 (Cx31). GJA1 (Cx43) was highly expressed throughout development (Fig. 4A). Microarray validation by qPCR of CLDN6, GJA1, and GJB1 showed similar results to those obtained by microarrays (Fig. 4B).

In many tissues, WNT signalling has been shown to play an important role in the proliferation and differentiation of undifferentiated progenitor and/or adult stem cells. Transcripts for several members of 
the WNT gene family were noted early in epididymal development. These included WNTs 4, 4.1, 5a, 6 and $9 \mathrm{~b}$. With the exception of WNT 5a, other Wnt members decreased after day 18. Members of the WNT receptor family, Frizzle (FZD), were also differentially expressed during development, with FZD 2, 4, and 10 being more highly expressed at day 7. FZD6 mRNA levels stayed fairly constant at all ages. Leucinerich repeat-containing G-protein coupled receptor 5 (LGR5), a R-Spondin-dependent plasma membrane protein linked to Wnt signalling, was also expressed predominantly at day 7. LGR5 has been shown to be a robust marker of adult stem cells in various tissues (Leung, et al., 2018). qPCR analyses of Wnt9b, and Fzd10 were used to confirm microarray data (Fig. 4B).

\section{Cell Signalling Pathways.}

Predicted signalling pathways using 1.5-fold differentially expressed genes were assessed using three separate software programs: DAVID (Huang da, Sherman and Lempicki, 2009a, Huang da, Sherman and Lempicki, 2009b), STRING (Szklarczyk, Gable, Lyon, Junge, Wyder, Huerta-Cepas, Simonovic, Doncheva, Morris, Bork, Jensen and Mering, 2019), and g:Profiler (Raudvere, Kolberg, Kuzmin, Arak, Adler, Peterson and Vilo, 2019). Kegg-enriched pathways consistently identified by all three different software programs are indicated in Supplemental Table VI. The data show that many more pathways were predicted when comparing gene expression in the 18 versus 7-day old rats. It is interesting to note that basal cell carcinoma signalling is identified, as this is the period of basal cell development in the epididymis. Comparisons of genes between days 7 and 60 also predict pathways associated with cell signalling, cell cycle, and p53 signalling, which may point to genes implicated in early columnar cell proliferation.

Membership analysis using Metascape shows that the differentially expressed genes (2-fold change) between days 18 and 7 are specifically enriched for the term "stem cell" and "thyroid hormone".

Throughout the development ( $d 18$ vs d7, d28 vs d18 and d60 vs d28), the regulated genes were enriched for the term "estrogen". The "androgen" membership was associated with differentially expressed genes from days 28 to 60 and days 18 to 28 while the search for "kidney differentiation" shows that this term is enriched in the differentially expressed genes from days 7 to 18 and days 18 to 28 (Table 1).

\section{Columnar Cell Organoids}

Microarray analyses clearly indicate the substantial changes that occur during epididymal development between days 7 and 18. The ability of these cells to form organoids in 3D cultures was assessed. Enzymatic digestion of epididymides from 7-day old rats into single cells cultured under 3D conditions in Matrigel resulted in the formation of sphere-like structures within 24 to 48 hours of culture (Fig. 5, IA). These continued to proliferate and expand in size. All of the organoids that were generated from single columnar cells expressed the stem cell marker LGR5 (Fig. 5 IB), identified in the microarray analysis. After 14 days of culture, a small portion ( $<10 \%$ ) of these organoids displayed immunostaining for Aquaporin 9 (AQP9), a marker of principal cells, or p63, a basal cell marker. A considerably larger fraction (almost $40 \%$ ) of organoids displayed immunostaining for V-ATPase (specifically, the ATP6V1B2 form), which has been associated with clear cells of the epididymis.

\section{Isolation of Columnar Cells}


Previous studies indicated that MACS isolation of basal cells with CD49f antibody resulted in highly enriched basal cell population (Mandon, Hermo and Cyr, 2015a). Immunostaining of epididymal sections from day 7 rats indicated an intense immunostaining of CD49f at the base of the epithelium. While there are no clearly identifiable basal cells in epididymides of day 7 rats, columnar cells appear to be positive

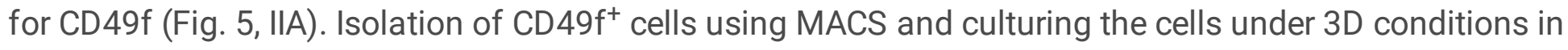
Matrigel indicated that only $\mathrm{CD}_{4} 9 \mathrm{f}^{+}$cells had the ability to form organoids (Fig. 5, IIB). Analysis by FACS of $\mathrm{CD}_{49 \mathrm{f}^{+}}$cells in day 10 epididymides suggest that there is a single population of $\mathrm{CD} 49 \mathrm{f}^{+}$cells and unlike other tissues of the urogenital tract (Santos, et al., 2019), we did not observe CD49f high and CD49f ${ }^{\text {low }}$ cells (Fig. 5, IIIA-C).

Coordinate positioning of cultured $\mathrm{Cd} 49 \mathrm{f}+$ columnar cells and following them over time confirmed that these organoids were derived from a single cell (Fig. 6A). Several markers of kidney development (Osr1, Lhx1, Wt1, Sall1) were also expressed in the epididymis and were significantly decreased at day 18 as compared with day 7. Signalling molecules and receptors implicated in kidney cell differentiation (Wnt9b, Wnt6, Wnt5a, Wnt2b, Wnt9a, RARa and Acvr1) showed a greater than 1.5-fold decrease at day 18 as compared to day 7 (Fig. 6B). We cultured CD $49 \mathrm{f}^{+}$cells from epididymides of day 7 rats in a culture medium previously used for growing and differentiating organoids derived from basal cells, as well as in a commercial medium used to differentiate kidney organoids, to which was added $10 \mathrm{nM}$ of DHT, previously reported to be essential for the differentiation of basal cells in vitro (Fig. 6C)(Mandon, Hermo and Cyr, 2015a). The results indicate that organoids could be derived from CD $49 f^{+}$epididymal cells in both control epididymal basal cell medium and commercial kidney stem cell medium. There was a significant $(p<0.01)$ increase in the number of organoids ranging in size between 40 and $80 \mu \mathrm{m}$, with a concomitant and significant $(p<0.05)$ decrease in the number of organoids $>80 \mu \mathrm{m}$, in organoids cultured in the commercial kidney medium, as compared to the control medium.

Irrespective of the culture medium, cells within differentiating organoids expressed p63, AQP9 and VATPase after 14 days of culture (Fig. 7A). However, the commercial kidney medium resulted in a significant increase in the number of organoids that were positive for either p63 or AQP9 (Fig. 7B). A much more important change in the number of V-ATPase positive organoids was also observed (Fig. 7B). mRNA levels of $p 63$ and $A Q P 9$ were also significantly increased by culture in kidney medium, although the levels of the ATP6V1B2 mRNA subunit of V-ATPase did not change. Taken together with the differences in immunostaining for various cell markers at day 14 , the data suggest that the kidney medium preferentially favored a trend towards a differentiation phase, while the basal cell medium promoted expansion and growth of these organoids.

\section{Discussion}

Our understanding of epididymal development and cellular differentiation has relied extensively on early morphological studies characterizing changes in the structure of undifferentiated short columnar cells, and their differentiation into basal cells and tall columnar/narrow cells which subsequently develop into

Page 12/34 
principal, clear, narrow and apical cells. The origin of epididymal dendritic cells remains to be clearly established, but these may represent cells initially identified by Cooper et al (Holschbach and Cooper, 2002) as blood-derived basal cells. Recent findings showed that epididymal basal cells share common properties with adult stem cells and can differentiate in vitro (Mandon, Hermo and Cyr, 2015a), in vivo using subcutaneous basal cell implants (Mou, Vinarsky, Tata, Brazauskas, Choi, Crooke, Zhang, Solomon, Turner, Bihler, Harrington, Lapey, Channick, Keyes, Freund, Artandi, Mense, Rowe, Engelhardt, Hsu and Rajagopal, 2016), and in basal cell-derived organoids under 3D cell culture conditions (Pinel, 2020). These recent observations have resulted in a need to re-evaluate cellular differentiation in the epididymis.

Epididymides of 7-day old rats are comprised of undifferentiated short columnar cells. Transcripts expressed at day 7 are heavily enriched with genes implicated in the cell cycle and stem cell signalling, supporting the previously reported morphological observations that the epithelium is largely undifferentiated at this age. Our microarray data demonstrate that numerous genes were highly expressed almost exclusively at day 7, including some of the gap junction proteins, cadherins (eg. $\mathrm{CDH}$, $\mathrm{CDH} 5$, and CDH6), claudin6 (CLDN6), a tight junction protein, and multiple proteins implicated in WNT signalling (WNT9b, Wnt6, LGR5, FZD2 and FZD10). CDH2 and CDH3 expression in undifferentiated columnar cells is interesting. These genes have been shown to be expressed in stem cells of the mammary gland, osteoblasts, chondrocytes, pro-myocytes and others (Alimperti and Andreadis, 2015, Patil, 2021, Ranjan, et al., 2021). Curiously, following the differentiation of basal cells, these genes become localized specifically to basal cells. LGR5 has been reported as a marker of adult stem cells in multiple tissues, including the intestine, bronchioles, mammary gland, and prostate (Barker and Clevers, 2010, de Visser, et al., 2012, Leung, Tan and Barker, 2018, Schuijers and Clevers, 2012, Seishima, et al., 2019).

Cellular differentiation of the epididymis is accompanied by dramatic changes in gene expression as the epithelium proliferates and differentiates. The largest changes in gene expression occurred between days 7 and 18, during which 1452 genes were differentially expressed, with 787 genes being down regulated and 665 genes being up-regulated. Downregulated genes at day 18 vs day 7 represented the major group of genes of the microarray analyses, showing the unique signature of the columnar cells.

Crisp1 (cysteine-rich secretory protein 1) and serpina16 (serine peptidase inhibitor, Clade A member 16) genes, also known as rat HongrES1(Ni, et al., 2009, Zhou, et al., 2008), showed the highest increase in mRNA levels between days 7 and 18 with over 95-fold increase, while Bin2a (beta-galactosidase-like protein), the third highest, showed a 63-fold increase (Supplemental Table III). All three genes have been shown to be androgen-responsive in the epididymis (Brooks, et al., 1986, Zhen, et al., 2009, Zhou, Zheng, Shi, Zhang, Zhen, Chen and Zhang, 2008). Other androgen-regulated genes such as Lcn5 (lipocalin 5), Adam7 (a disintegrin and metallopeptidase domain 7), DEFB1 (defensin beta 1), AQP9, Spink13 (serine peptidase inhibitor, Kazal type 13), and several DEFB (Hu, et al., 2014, Ma, et al., 2013) were also highly upregulated from 7 to 18 days (Lareyre, et al., 2000, Ma, Yu, Ni, Hu, Ma, Chu, Liu and Zhang, 2013, Oh, et al., 2005, Oliveira, et al., 2005, Palladino, et al., 2004), suggesting that early development is strongly influenced by androgens, even though androgen levels have been reported as being low at this age 
(Scheer and Robaire, 1980). Furthermore, while transcripts for the androgen receptor increase only slightly by day 18, there is a 10-fold increase in type 2 4-ene-5-alpha-reductase (SRD5a) (Viger and Robaire, 1995, Viger and Robaire, 1996). While expression levels of many of these genes further increase by day 28 , the results show that androgen regulation in the epididymis begins at these early stages of development, prior to the presence of morphologically distinct principal cells (Sun and Flickinger, 1979).

Of the 787 down regulated genes in the 7 to 18 -day period, 41 were downregulated by a factor of 5 -fold of more. The transcription factor FOS (FBJ osteosarcoma oncogene), which has been shown to be androgen-repressed (Shankar, et al., 2016), displayed the highest degree of downregulation, 14.5-fold. In contrast to the upregulated genes associated with androgen regulation in the epididymis, there was no obvious pattern of regulation with the most highly downregulated genes.

Interestingly, several imprinted genes were downregulated at 18 days: DLK1 (delta like non-canonical Notch ligand 1) with a fold change of -7.75 , the GNAS complex locus with a fold change of -6.79 , and IGF2 (insulin-like growth factor 2) with a fold change of -6.26 . DLK1 regulates cell differentiation and developmental processes through Notch and other signalling pathways (Traustadottir, et al., 2019). Igf-2 is almost exclusively expressed in the embryo of rodents (Chao and D'Amore, 2008). AGTR2 (angiotensin II receptor, type 2), which is a basal cell marker, was also decreased (fold change of -4.8 , (Shum, et al., 2008)), as was Osr1 (odd-skipped related transcription factor 1; fold change of -4.35), a transcription factor implicated in normal development and organogenesis of the heart and kidney (Wang, et al., 2005). Numerous V-ATPases were found to be upregulated at day 18 (Fig. 3A).

During the period of cell differentiation, days 18 and 28, our results indicated 344 upregulated and 327 downregulated genes. Of the most highly expressed genes, epididymis-specific Gpx5 (glutathione peroxidase 5), an androgen- and testicular factors-regulated gene (Drevet, et al., 1998), showed the highest increase, with a fold change of 62.61 . Rat Gpx 5 transcripts were previously detected at day 32 by RT-PCR, before the appearance of the protein in the epididymis at day 44 , just prior to puberty and the entry of sperm in the epididymis (Williams, et al., 1998). Other sperm-binding molecules and androgenregulated genes also showed increased transcripts levels, including multiple defensins, Crisp4 and Pate (prostate and testis expressed) proteins (Hu, Zou, Yao, Ma, Zhu, Li, Chen and Sun, 2014, Jalkanen, et al., 2005, Turunen, et al., 2011). The Gammaaminobutyric acid (GABA-A) receptor pi (GABRP) was decreased by 9.48 -fold. This receptor subunit has been shown to be implicated in airway epithelial progenitor cell differentiation (Wang, et al., 2021). WNT9b (wingless-type MMTV integration site family, member 9B), CLDN6 (claudin 6) and CFTR (cystic fibrosis transmembrane conductance regulator) were also downregulated from 18 to 28 days, with a fold change of $-6.25,-4.22$, and -3.19 , respectively.

There were 406 upregulated and 154 downregulated genes between days 60 and 28. Many of these included defensins (Ribeiro, Silva, Hinton and Avellar, 2016), lipocalins (Fouchecourt, Lareyre, Chaurand, DaGue, Suzuki, Ong, Olson, Matusik, Caprioli and Orgebin-Crist, 2003) and a transcript encoding a protein of the specialized mitochondria present in the midpiece of the sperm flagella, SMCP (sperm mitochondria-associated cysteine-rich protein (Kleene, Wang, Cutler, Hall and Shih, 1994). SMCP 
transcripts are present in round spermatids, where they are translationally repressed and are transcribed in elongated spermatids (Kleene, 1989). Légaré et al. (Legare, et al., 2017) detected the SMCP transcripts in the bovine caput epididymides.

Pathway associations using Metascape analyses indicated that in epididymides of 7 to 18-day old rats, there was a significant enrichment of regulated genes implicated in stem cells, estrogen, thyroid hormone and kidney development. This is consistent with previous observations that have reported the differentiation of small epididymal columnar cells into other cell types, as well as implicating a role for estrogens and thyroid hormones in epididymal development (Anbalagan, et al., 2010, De Paul, et al., 2008, Hess, Sharpe and Hinton, 2021, St-Pierre, et al., 2003, Sun and Flickinger, 1979). Similarities between epididymal and renal development may be related to the common embryonic mesonephric origin of both tissues. The influence of estrogens on the epididymis appeared to extend throughout all phases of development and cell differentiation (Hess, 2000, Hess, Sharpe and Hinton, 2021). Unlike estrogens, androgen-dependent genes displayed significant changes between days 28 and 18 and 60 and 28 . However, some androgen-dependent epididymal genes showed considerably increased gene expression between days 28 and 18, and may represent highly sensitive transcriptional activation of certain genes to low levels of androgens. Surprisingly, there were no significant associations in cell junctions, epidermal growth factor or immune function genes. While many of these genes showed differential expression, it is possible that only a few key specific genes are altered during development, or that these occur in a segment-specific manner and were not detected with the current experimental protocol using the entire epididymis.

Immune cells of the epididymis, such as dendritic cells and macrophages, can produce inflammatory cytokines implicated in the immune response. Transcript levels for the cytokines IL1 alpha and beta, IL6, IL10, IL12 and IL20, as well as for interferon gamma and tumor necrosis factor, were expressed at low levels throughout development. Expression of the tryptophan-depleting enzymes (indoleamine 2,3dioxygenases (Ido1 and Ido2) increased during epididymal development. These enzymes are recognized to be implicated in the regulation of the equilibrium between the immune response and self-tolerance (Jrad-Lamine, et al., 2011, Mehraj, et al., 2020), which is an important mechanism for sperm maturation. Transforming growth factor-beta ligands 1, 2 and 3 were expressed at similar levels at day 7 in the epididymis. Transforming growth factor beta1 (TGFb1) mRNAs showed a constant level of expression throughout development, while TGFb2 and 3 mRNA levels decreased slightly. The TGFb pathway has been shown to be implicated in the immunotolerance to sperm in mice (Pierucci-Alves, et al., 2018).

Innate immune receptors to pathogens, Toll-like receptors (TLRs) 1 to 11 are expressed in the epididymis (Liman, et al., 2019, Munipalli, et al., 2019, Rodrigues, et al., 2008). Microarray data indicated that TLR3 and 5 were the most highly expressed in the epididymis. TLR3 has the highest level of expression throughout the development, and TLR5 increased with age. TLR8 and 9 were not probed by the microarray. Nuclear factor kappa B subunits 1 and 2 (NFkB1 and NFkB2) were detected at all time points of epididymal development used in this study. The alpha inhibitor (NFkBia) was also highly expressed at days 7 and 18 and decreased at days 28 and 60 (Gregory and Cyr, 2014).

Page $15 / 34$ 
The widespread immunostaining for V-ATPase observed in undifferentiated organoids derived from CD49f+epididymal cells from day 7 rats suggests that as the epididymal epithelium develops postnatally, many cells destined for further differentiation express this protein. Whether or not this is a transient type of previously-undescribed cell, or rather a stage of basal-type cells, is unknown. Numerous V-ATPases were also upregulated between day 7 and 18 . There are reports in the literature regarding the expression of V-ATPase (various isoforms) as a function of differentiation in multiple tissues and/or cell types. Wissel et al (Wissel, et al., 2018) have reported a V-ATPase-NOTCH regulatory loop in Drosophila neural stem cells or neuroblasts. They and others suggest that V-ATPase and NOTCH act in multiple stem cell lineages during nervous system and adult gut development. Although various subunits or isoforms of V-ATPase family members are implicated in many cellular processes (McGuire, et al., 2017, Sun-Wada and Wada, 2015), the authors of the Drosophila studies suggest that the V-ATPase complex is required for self-renewal-of the neuroblast stem cells. Furthermore, they report that it is among the first and mostsignificantly down-regulated complex in differentiating daughter cells, and that it is necessary for maintaining NOTCH pathway activity.

V-ATPase (multiple isoforms) is associated with luminal acidification, which is critical in the epididymis and other tissues (Breton and Brown, 2013, Shum, et al., 2011). This luminal acidification is necessary for preserving spermatozoa in a quiescent state. However, multiple isoforms of V-ATPase in the epididymis have been reported in the literature (Pietrement, et al., 2006), which prompts the question of whether or not these multiple isoforms have different functions. V-ATPase subunits can interact with some enzymes that are part of the glycolytic pathway in mammalian cells (Breton and Brown, 2007). Intriguingly, another group has examined the roles of glucose metabolism, fatty acid oxidation, and reactive oxygen species (ROS) in the equilibrium between quiescence and self-renewal of adult stem cells (Mohammad, et al., 2019). The authors point out that low ROS is a hallmark of adult stem cells. This would align with a role for V-ATPase in maintaining $\mathrm{pH}$ and protecting cells from ROS damage, as well as promoting self-renewal of stem cells. Nonetheless, the fact that organoids derived from basal cells of adult rats also expressed VATPase to a significant degree (Pinel, 2020), as well as organoids cultured in either epididymal basal cell medium or the commercial kidney medium, further supports the notion that the expression of V-ATPase is, at the very least, an indicator of self-renewal of at least a subset of stem cells, and perhaps also suggests a transient phase of cellular differentiation.

In conclusion, the development of the epididymal epithelium and subsequent cellular differentiation into multiple specialized cell types is a complex, highly-coordinated process which relies on a variety of cues from the physiological environment as well as from numerous signalling pathways. We have identified multiple key signalling pathways involved in the various stages of epididymal epithelial development and differentiation. Information from our microarray and PCR analyses highlight the genes which play major roles at specific time points during development. Furthermore, we have developed a new in vitro model of epididymal organoids, derived from undifferentiated Cd49f-positive columnar cells. Finally, we have provided evidence of the stem cell-like properties of these cells, and have provided methods for both proliferation as well as differentiation of these columnar cells into other cell types. We believe that these data significantly advance our understanding of epididymal epithelial development and differentiation. 


\section{Declarations}

Acknowledgement: The assistance of T. El Belaidi and S. Pinto (INRS) is appreciated. J. Tremblay (INRS) is thanked for his assistance with confocal microscopy and flow cytometry.

Data Availability: The gene expression data from transcriptomic analyses have been deposited in the National Center for Biotechnology Information's Gene Expression Omnibus (GEO, http://www.ncbi.nlm.nih.gov/geo/) and are accessible through GEO accession number GSE193653. Other data are available from the corresponding author.

\section{Compliance with Ethical Standards}

Conflicts of Interest: The authors declare that there is no financial or non-financial conflict of interest.

Funding: The study was funded by grants to DGC from the Canadian Institutes for Health Research (84576), Natural Sciences and Engineering Research Council (155065-06) and Canada Research Chairs Program. LP is the recipient of a studentship from the Fonds de Recherches du Québec-Nature et Technologie -Réseau Québec en Reproduction.

Ethical Approval: All the animal protocols used in this study were approved by the Institut National de la recherche Scientifique (INRS) university animal care committee according to the guidelines of the Canadian Council on Animal Care.

Informed Consent: All participants have given their verbal consent regrading their participation in this study and submission of this article.

\section{References}

1. Alimperti S, Andreadis ST (2015) $\mathrm{CDH} 2$ and $\mathrm{CDH} 11$ act as regulators of stem cell fate decisions. Stem Cell Res 14:270-282

2. Anbalagan J, Sashi AM, Vengatesh G, Stanley JA, Neelamohan R, Aruldhas MM (2010) Mechanism underlying transient gestational-onset hypothyroidism-induced impairment of posttesticular sperm maturation in adult rats. Fertil Steril 93:2491-2497

3. Babicki S, Arndt D, Marcu A, Liang Y, Grant JR, Maciejewski A, Wishart DS (2016) Heatmapper: webenabled heat mapping for all. Nucleic Acids Res 44:W147-153

4. Barker N, Clevers H (2010) Leucine-rich repeat-containing G-protein-coupled receptors as markers of adult stem cells. Gastroenterology 138:1681-1696

5. Brazma A, Hingamp P, Quackenbush J, Sherlock G, Spellman P, Stoeckert C, Aach J, Ansorge W, Ball CA, Causton HC, Gaasterland T, Glenisson P, Holstege FC, Kim IF, Markowitz V, Matese JC, Parkinson H, Robinson A, Sarkans U, Schulze-Kremer S, Stewart J, Taylor R, Vilo J, Vingron M (2001) Minimum information about a microarray experiment (MIAME)-toward standards for microarray data. Nature genetics 29:365-371 
6. Breton S, Brown D (2007) New insights into the regulation of V-ATPase-dependent proton secretion. Am J Physiol Renal Physiol 292:F1-10

7. Breton S, Brown D (2013) Regulation of luminal acidification by the V-ATPase. Physiology (Bethesda) 28:318-329

8. Breton S, Ruan YC, Park YJ, Kim B (2016) Regulation of epithelial function, differentiation, and remodeling in the epididymis. Asian J Androl 18:3-9

9. Brooks DE, Means AR, Wright EJ, Singh SP, Tiver KK (1986) Molecular cloning of the cDNA for two major androgen-dependent secretory proteins of 18.5 kilodaltons synthesized by the rat epididymis. J Biol Chem 261:4956-4961

10. Browne JA, Leir SH, Yin S, Harris A (2019) Transcriptional networks in the human epididymis. Andrology 7:741-747

11. Chao W, D'Amore PA (2008) IGF2: epigenetic regulation and role in development and disease. Cytokine Growth Factor Rev 19:111-120

12. Cornwall GA (2009) New insights into epididymal biology and function. Hum Reprod Update 15:213227

13. Cyr DG, Dufresne J, Gregory M (2018) Cellular junctions in the epididymis, a critical parameter for understanding male reproductive toxicology. Reprod Toxicol 81:207-219

14. Cyr DG, Gregory M, Dube E, Dufresne J, Chan PT, Hermo L (2007) Orchestration of occludins, claudins, catenins and cadherins as players involved in maintenance of the blood-epididymal barrier in animals and humans. Asian J Androl 9:463-475

15. De Paul AL, Mukdsi JH, Pellizas CG, Montesinos M, Gutierrez S, Susperreguy S, Del Rio A, Maldonado CA, Torres Al (2008) Thyroid hormone receptor alpha 1-beta 1 expression in epididymal epithelium from euthyroid and hypothyroid rats. Histochem Cell Biol 129:631-642

16. de Visser KE, Ciampricotti M, Michalak EM, Tan DW, Speksnijder EN, Hau CS, Clevers H, Barker N, Jonkers J (2012) Developmental stage-specific contribution of LGR5(+) cells to basal and luminal epithelial lineages in the postnatal mammary gland. J Pathol 228:300-309

17. Drevet JR, Lareyre JJ, Schwaab V, Vernet P, Dufaure JP (1998) The PEA3 protein of the Ets oncogene family is a putative transcriptional modulator of the mouse epididymis-specific glutathione peroxidase gene gpx5. Mol Reprod Dev 49:131-140

18. Dube E, Chan PT, Hermo L, Cyr DG (2007) Gene expression profiling and its relevance to the bloodepididymal barrier in the human epididymis. Biol Reprod 76:1034-1044

19. Dube E, Cyr DG (2012) The blood-epididymis barrier and human male fertility. Adv Exp Med Biol 763:218-236

20. Elbashir S, Magdi Y, Rashed A, Henkel R, Agarwal A (2021) Epididymal contribution to male infertility: An overlooked problem. Andrologia 53:e13721

21. Fouchecourt S, Lareyre JJ, Chaurand P, DaGue BB, Suzuki K, Ong DE, Olson GE, Matusik RJ, Caprioli RM, Orgebin-Crist MC (2003) Identification, immunolocalization, regulation, and postnatal 
development of the lipocalin EP17 (epididymal protein of 17 kilodaltons) in the mouse and rat epididymis. Endocrinology 144:887-900

22. Girardet L, Bernet A, Calvo E, Soulet D, Joly-Beauparlant C, Droit A, Cyr DG, Belleannee C (2020) Hedgehog signaling pathway regulates gene expression profile of epididymal principal cells through the primary cilium. FASEB J 34:7593-7609

23. Gregory M, Cyr DG (2014) The blood-epididymis barrier and inflammation. Spermatogenesis 4:e979619

24. Gregory M, Cyr DG (2019) Effects of prostaglandin E2 on gap junction protein alpha 1 in the rat epididymis. Biol Reprod 100:123-132

25. Hayashi T, Yoshinaga A, Ohno R, Ishii N, Kamata S, Yamada T (2004) Expression of the p63 and Notch signaling systems in rat testes during postnatal development: comparison with their expression levels in the epididymis and vas deferens. J Androl 25:692-698

26. Hejmej A, Bilinska B (2018) The effects of flutamide on cell-cell junctions in the testis, epididymis, and prostate. Reprod Toxicol 81:1-16

27. Hermo L, Barin K, Robaire B (1992) Structural differentiation of the epithelial cells of the testicular excurrent duct system of rats during postnatal development. Anat Rec 233:205-228

28. Hess RA (2000) Oestrogen in fluid transport in efferent ducts of the male reproductive tract. Rev Reprod 5:84-92

29. Hess RA, Sharpe RM, Hinton BT (2021) Estrogens and development of the rete testis, efferent ductules, epididymis and vas deferens. Differentiation 118:41-71

30. Holschbach C, Cooper TG (2002) A possible extratubular origin of epididymal basal cells in mice. Reproduction 123:517-525

31. Hosack DA, Dennis G, Jr., Sherman BT, Lane HC, Lempicki RA (2003) Identifying biological themes within lists of genes with EASE. Genome Biol 4:R70

32. Hu SG, Zou M, Yao GX, Ma WB, Zhu QL, Li XQ, Chen ZJ, Sun Y (2014) Androgenic regulation of betadefensins in the mouse epididymis. Reprod Biol Endocrinol 12:76

33. Huang da W, Sherman BT, Lempicki RA (2009a) Bioinformatics enrichment tools: paths toward the comprehensive functional analysis of large gene lists. Nucleic Acids Res 37:1-13

34. Huang da W, Sherman BT, Lempicki RA (2009b) Systematic and integrative analysis of large gene lists using DAVID bioinformatics resources. Nat Protoc 4:44-57

35. Jalkanen J, Huhtaniemi I, Poutanen M (2005) Discovery and characterization of new epididymisspecific beta-defensins in mice. Biochim Biophys Acta 1730:22-30

36. Jones RC, Dacheux JL, Nixon B, Ecroyd HW (2007) Role of the epididymis in sperm competition. Asian J Androl 9:493-499

37. Jrad-Lamine A, Henry-Berger J, Gourbeyre P, Damon-Soubeyrand C, Lenoir A, Combaret L, Saez F, Kocer A, Tone S, Fuchs D, Zhu W, Oefner PJ, Munn DH, Mellor AL, Gharbi N, Cadet R, Aitken RJ, Drevet 
JR (2011) Deficient tryptophan catabolism along the kynurenine pathway reveals that the epididymis is in a unique tolerogenic state. J Biol Chem 286:8030-8042

38. Kim JK, Vinarsky V, Wain J, Zhao R, Jung K, Choi J, Lam A, Pardo-Saganta A, Breton S, Rajagopal J, Yun SH (2012) In vivo imaging of tracheal epithelial cells in mice during airway regeneration. Am J Respir Cell Mol Biol 47:864-868

39. Kleene KC (1989) Poly(A) shortening accompanies the activation of translation of five mRNAs during spermiogenesis in the mouse. Development 106:367-373

40. Kleene KC, Wang MY, Cutler M, Hall C, Shih D (1994) Developmental expression of poly(A) binding protein mRNAs during spermatogenesis in the mouse. Mol Reprod Dev 39:355-364

41. Lareyre JJ, Reid K, Nelson C, Kasper S, Rennie PS, Orgebin-Crist MC, Matusik RJ (2000) Characterization of an androgen-specific response region within the $5^{\prime}$ flanking region of the murine epididymal retinoic acid binding protein gene. Biol Reprod 63:1881-1892

42. Legare C, Akintayo A, Blondin P, Calvo E, Sullivan R (2017) Impact of male fertility status on the transcriptome of the bovine epididymis. Mol Hum Reprod 23:355-369

43. Leung C, Tan SH, Barker N (2018) Recent Advances in Lgr5(+) Stem Cell Research. Trends Cell Biol 28:380-391

44. Liman N, Alan E, Apaydin N (2019) The expression and localization of Toll-like receptors 2, 4, 5 and 9 in the epididymis and vas deferens of a adult tom cats. Theriogenology 128:62-73

45. Ma L, Yu H, Ni Z, Hu S, Ma W, Chu C, Liu Q, Zhang Y (2013) Spink13, an epididymis-specific gene of the Kazal-type serine protease inhibitor (SPINK) family, is essential for the acrosomal integrity and male fertility. J Biol Chem 288:10154-10165

46. Mandon M, Hermo L, Cyr DG (2015a) Isolated Rat Epididymal Basal Cells Share Common Properties with Adult Stem Cells. Biol Reprod 93:115

47. Mandon M, Hermo L, Cyr DG (2015b) Isolated Rat Epididymal Basal Cells Share Common Properties with Adult Stem Cells. Biol Reprod 93:115-130

48. McGuire C, Stransky L, Cotter K, Forgac M (2017) Regulation of V-ATPase activity. Front Biosci (Landmark Ed) 22:609-622

49. Mehraj V, Ramendra R, Isnard S, Dupuy FP, Ponte R, Chen J, Kema I, Jenabian MA, Costinuik CT, Lebouche B, Thomas R, Cote P, Leblanc R, Baril JG, Durand M, Chartrand-Lefebvre C, Tremblay C, Ancuta P, Bernard NF, Sheppard DC, Routy JP, Montreal Primary HIVIS, Canadian HIV, Aging Cohort Study G (2020) Circulating (1->3)-beta-D-glucan Is Associated With Immune Activation During Human Immunodeficiency Virus Infection. Clin Infect Dis 70:232-241

50. Mi H, Ebert D, Muruganujan A, Mills C, Albou LP, Mushayamaha T, Thomas PD (2021) PANTHER version 16: a revised family classification, tree-based classification tool, enhancer regions and extensive API. Nucleic Acids Res 49:D394-D403

51. Mohammad K, Dakik P, Medkour Y, Mitrofanova D, Titorenko VI (2019) Quiescence Entry, Maintenance, and Exit in Adult Stem Cells. Int J Mol Sci 20: 
52. Mou H, Vinarsky V, Tata PR, Brazauskas K, Choi SH, Crooke AK, Zhang B, Solomon GM, Turner B, Bihler H, Harrington J, Lapey A, Channick C, Keyes C, Freund A, Artandi S, Mense M, Rowe S, Engelhardt JF, Hsu YC, Rajagopal J (2016) Dual SMAD Signaling Inhibition Enables Long-Term Expansion of Diverse Epithelial Basal Cells. Cell Stem Cell 19:217-231

53. Munipalli SB, Mounika MR, Aisha J, Yenugu S (2019) TIr1-13, Nod1/2 and antimicrobial gene expression in the epididymis and testis of rats with alloxan-induced diabetes. Andrologia 51:e13437

54. Murashima A, Kishigami S, Thomson A, Yamada G (2015) Androgens and mammalian male reproductive tract development. Biochim Biophys Acta 1849:163-170

55. Murashima A, Miyagawa S, Ogino Y, Nishida-Fukuda H, Araki K, Matsumoto T, Kaneko T, Yoshinaga K, Yamamura K, Kurita T, Kato S, Moon AM, Yamada G (2011) Essential roles of androgen signaling in Wolffian duct stabilization and epididymal cell differentiation. Endocrinology 152:1640-1651

56. Ni Y, Zhou Y, Chen WY, Zheng M, Yu J, Li C, Zhang Y, Shi QX (2009) HongrES1, a cauda epididymisspecific protein, is involved in capacitation of guinea pig sperm. Mol Reprod Dev 76:984-993

57. Oh J, Woo JM, Choi E, Kim T, Cho BN, Park ZY, Kim YC, Kim DH, Cho C (2005) Molecular, biochemical, and cellular characterization of epididymal ADAMs, ADAM7 and ADAM28. Biochem Biophys Res Commun 331:1374-1383

58. Oliveira CA, Carnes K, Franca LR, Hermo L, Hess RA (2005) Aquaporin-1 and -9 are differentially regulated by oestrogen in the efferent ductule epithelium and initial segment of the epididymis. Biol Cell 97:385-395

59. Palladino MA, Powell JD, Korah N, Hermo L (2004) Expression and localization of hypoxia-inducible factor-1 subunits in the adult rat epididymis. Biol Reprod 70:1121-1130

60. Patil S (2021) CD44 Sorted Cells Have an Augmented Potential for Proliferation, EpithelialMesenchymal Transition, Stemness, and a Predominantly Inflammatory Cytokine and Angiogenic Secretome. Curr Issues Mol Biol 43:423-433

61. Pierucci-Alves F, Midura-Kiela MT, Fleming SD, Schultz BD, Kiela PR (2018) Transforming Growth Factor Beta Signaling in Dendritic Cells Is Required for Immunotolerance to Sperm in the Epididymis. Front Immunol 9:1882

62. Pietrement C, Sun-Wada GH, Silva ND, McKee M, Marshansky V, Brown D, Futai M, Breton S (2006) Distinct expression patterns of different subunit isoforms of the V-ATPase in the rat epididymis. Biol Reprod 74:185-194

63. Pinel L, Mandon M, Cyr DG (2019) Tissue regeneration and the epididymal stem cell. Andrology 7:618-630

64. Pinel LC, D.G. (2020) Self-renewal and differentiation of rat epididymal basal cells using a novel in vitro organoid model Biol Reprod (Accepatble with revisions)

65. Ranjan M, Lee O, Cottone G, Mirzaei Mehrabad E, Spike BT, Zeng Z, Yadav S, Chatterton R, Kim JJ, Clare SE, Khan SA (2021) Progesterone receptor antagonists reverse stem cell expansion and the paracrine effectors of progesterone action in the mouse mammary gland. Breast Cancer Res 23:78 
66. Raudvere U, Kolberg L, Kuzmin I, Arak T, Adler P, Peterson H, Vilo J (2019) g:Profiler: a web server for functional enrichment analysis and conversions of gene lists (2019 update). Nucleic Acids Res 47:W191-W198

67. Ribeiro CM, Ferreira LG, Thimoteo DS, Smith LB, Hinton BT, Avellar MC (2017) Novel androgeninduced activity of an antimicrobial beta-defensin: Regulation of Wolffian duct morphogenesis. Mol Cell Endocrinol 442:142-152

68. Ribeiro CM, Silva EJ, Hinton BT, Avellar MC (2016) beta-defensins and the epididymis: contrasting influences of prenatal, postnatal, and adult scenarios. Asian J Androl 18:323-328

69. Robaire B, Hinton BT (2015) The Epididymis. In: Plant T, Zeleznik A (eds) Knobil and Neill's Reproductive Physiology. Academic Press, New York, pp 691-771

70. Rock JR, Randell SH, Hogan BL (2010) Airway basal stem cells: a perspective on their roles in epithelial homeostasis and remodeling. Dis Model Mech 3:545-556

71. Rodrigues A, Queiroz DB, Honda L, Silva EJ, Hall SH, Avellar MC (2008) Activation of toll-like receptor 4 (TLR4) by in vivo and in vitro exposure of rat epididymis to lipopolysaccharide from Escherichia Coli. Biol Reprod 79:1135-1147

72. Rodriguez CMK, J.L.; Hinton, B.T. (2002) The Development of the Epididymis. In: Robaire BH, B.T. (ed) The Epididymis: From Molecules to Clinical Practice. Kluwer Academic/Plenum Publishers, New York, pp 251-268

73. Roomans GM (2010) Tissue engineering and the use of stem/progenitor cells for airway epithelium repair. Eur Cell Mater 19:284-299

74. Saito K, Kawakami S, Okada Y, Takazawa R, Koga F, Kageyama Y, Kihara K (2006) Spatial and isoform specific p63 expression in the male human urogenital tract. J Urol 176:2268-2273

75. Santos CP, Lapi E, Martinez de Villarreal J, Alvaro-Espinosa L, Fernandez-Barral A, Barbachano A, Dominguez O, Laughney AM, Megias D, Munoz A, Real FX (2019) Urothelial organoids originating from Cd49f(high) mouse stem cells display Notch-dependent differentiation capacity. Nat Commun 10:4407

76. Scheer H, Robaire B (1980) Steroid delta 4-5 alpha-reductase and 3 alpha-hydroxysteroid dehydrogenase in the rat epididymis during development. Endocrinology 107:948-953

77. Schuijers J, Clevers H (2012) Adult mammalian stem cells: the role of Wnt, Lgr5 and R-spondins. EMBO J 31:2685-2696

78. Seishima R, Leung C, Yada S, Murad KBA, Tan LT, Hajamohideen A, Tan SH, Itoh H, Murakami K, Ishida Y, Nakamizo S, Yoshikawa Y, Wong E, Barker N (2019) Neonatal Wnt-dependent Lgr5 positive stem cells are essential for uterine gland development. Nature communications 10:5378

79. Shankar E, Song K, Corum SL, Bane KL, Wang H, Kao HY, Danielpour D (2016) A Signaling Network Controlling Androgenic Repression of c-Fos Protein in Prostate Adenocarcinoma Cells. J Biol Chem 291:5512-5526

80. Shum WW, Da SN, Belleannee C, McKee M, Brown D, Breton S (2011) Regulation of V-ATPase recycling via a RhoA- and ROCKII-dependent pathway in epididymal clear cells. Am J Physiol Cell 
Physiol 301:C31-C43

81. Shum WW, Da SN, McKee M, Smith PJ, Brown D, Breton S (2008) Transepithelial projections from basal cells are luminal sensors in pseudostratified epithelia. Cell 135:1108-1117

82. Sipila P, Bjorkgren I (2016) Segment-specific regulation of epididymal gene expression. Reproduction 152:R91-99

83. St-Pierre N, Dufresne J, Rooney AA, Cyr DG (2003) Neonatal hypothyroidism alters the localization of gap junctional protein connexin 43 in the testis and messenger RNA levels in the epididymis of the rat. Biol Reprod 68:1232-1240

84. Sun-Wada GH, Wada Y (2015) Role of vacuolar-type proton ATPase in signal transduction. Biochim Biophys Acta 1847:1166-1172

85. Sun EL, Flickinger CJ (1979) Development of cell types and of regional differences in the postnatal rat epididymis. Am J Anat 154:27-55

86. Szklarczyk D, Gable AL, Lyon D, Junge A, Wyder S, Huerta-Cepas J, Simonovic M, Doncheva NT, Morris JH, Bork P, Jensen LJ, Mering CV (2019) STRING v11: protein-protein association networks with increased coverage, supporting functional discovery in genome-wide experimental datasets. Nucleic Acids Res 47:D607-D613

87. Traustadottir GA, Lagoni LV, Ankerstjerne LBS, Bisgaard HC, Jensen CH, Andersen DC (2019) The imprinted gene Delta like non-canonical Notch ligand 1 (Dlk1) is conserved in mammals, and serves a growth modulatory role during tissue development and regeneration through Notch dependent and independent mechanisms. Cytokine Growth Factor Rev 46:17-27

88. Turner TT, Johnston DS, Finger JN, Jelinsky SA (2007) Differential gene expression among the proximal segments of the rat epididymis is lost after efferent duct ligation. Biol Reprod 77:165-171

89. Turunen HT, Sipila P, Pujianto DA, Damdimopoulos AE, Bjorkgren I, Huhtaniemi I, Poutanen M (2011) Members of the murine Pate family are predominantly expressed in the epididymis in a segmentspecific fashion and regulated by androgens and other testicular factors. Reprod Biol Endocrinol $9: 128$

90. Viger RS, Robaire B (1995) Steady state steroid 5 alpha-reductase messenger ribonucleic acid levels and immunocytochemical localization of the type 1 protein in the rat testis during postnatal development. Endocrinology 136:5409-5415

91. Viger RS, Robaire B (1996) The mRNAs for the steroid 5 alpha-reductase isozymes, types 1 and 2 , are differentially regulated in the rat epididymis. J Androl 17:27-34

92. Wang A, Zhang Q, Wang Y, Li X, Li K, Li Y, Wang J, Li L, Chen H (2021) Inhibition of Gabrp reduces the differentiation of airway epithelial progenitor cells into goblet cells. Exp Ther Med 22:720

93. Wang Q, Lan Y, Cho ES, Maltby KM, Jiang R (2005) Odd-skipped related 1 (Odd 1) is an essential regulator of heart and urogenital development. Dev Biol 288:582-594

94. Williams K, Frayne J, Hall L (1998) Expression of extracellular glutathione peroxidase type 5 (GPX5) in the rat male reproductive tract. Mol Hum Reprod 4:841-848 
95. Wissel S, Harzer H, Bonnay F, Burkard TR, Neumuller RA, Knoblich JA (2018) Time-resolved transcriptomics in neural stem cells identifies a v-ATPase/Notch regulatory loop. J Cell Biol 217:3285-3300

96. Xu B, Turner SD, Hinton BT (2018) Alteration of transporter activities in the epididymides of infertile initial segment-specific Pten knockout mice. Biol Reprod

97. Xu B, Washington AM, Hinton BT (2014) PTEN signaling through RAF1 proto-oncogene serine/threonine kinase (RAF1)/ERK in the epididymis is essential for male fertility. Proc Natl Acad Sci U S A 111:18643-18648

98. Xu B, Yang L, Lye RJ, Hinton BT (2010) p-MAPK1/3 and DUSP6 regulate epididymal cell proliferation and survival in a region-specific manner in mice. Biol Reprod 83:807-817

99. Zhen W, Li P, He B, Guo J, Zhang YL (2009) The novel epididymis-specific beta-galactosidase-like gene Glb1/4 is essential in epididymal development and sperm maturation in rats. Biol Reprod 80:696-706

100. Zhou Y, Zheng M, Shi Q, Zhang L, Zhen W, Chen W, Zhang Y (2008) An epididymis-specific secretory protein HongrES1 critically regulates sperm capacitation and male fertility. PLoS One 3:e4106

101. Zhou Y, Zhou B, Pache L, Chang M, Khodabakhshi AH, Tanaseichuk O, Benner C, Chanda SK (2019) Metascape provides a biologist-oriented resource for the analysis of systems-level datasets. Nat Commun 10:1523

\section{Table 1}

Table 1 is available in the Supplementary Files section.

\section{Figures}


A

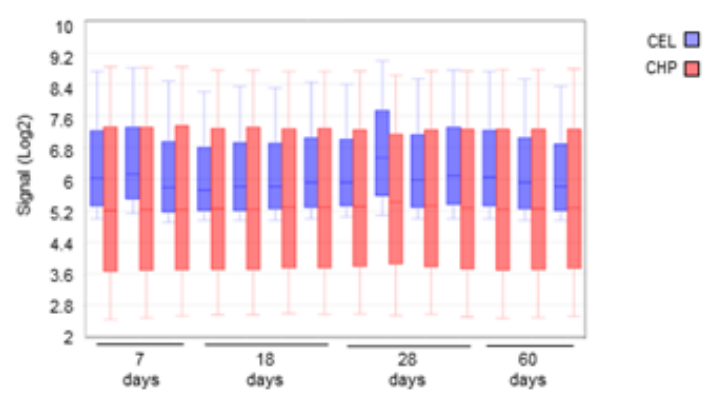

B

PCA Mapping $78.8 \%$ (CHP)
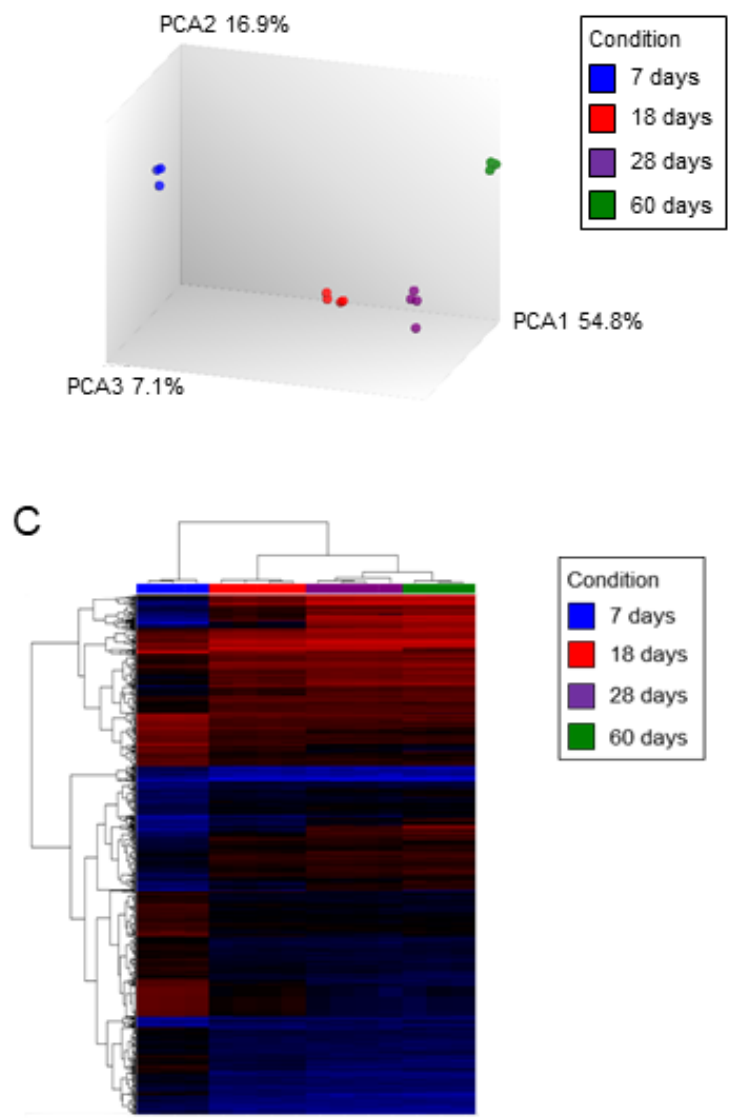

\section{Figure 1}

Microarray data of 7-, 18-, 28- and 60-d old rat epididymides RNA transcripts. A) Box plot visualization of distribution of intensities for each sample. The blue boxes represent the CEL files of raw intensities and the red boxes, the background corrected, normalized and summarized CHP files following RMA. B) Principal component analysis of summarized CHP data performed on a maximum number of 5000 data points evenly distributed for each microarray sample. C) Heat map and hierarchical cluster analysis of 
1009 genes differentially expressed (2-fold change) in the epididymis of 7-, 18-, 28- and 60-day old rats. Genes expressed at levels above the average are represented in red, below average in blue, and average in black.
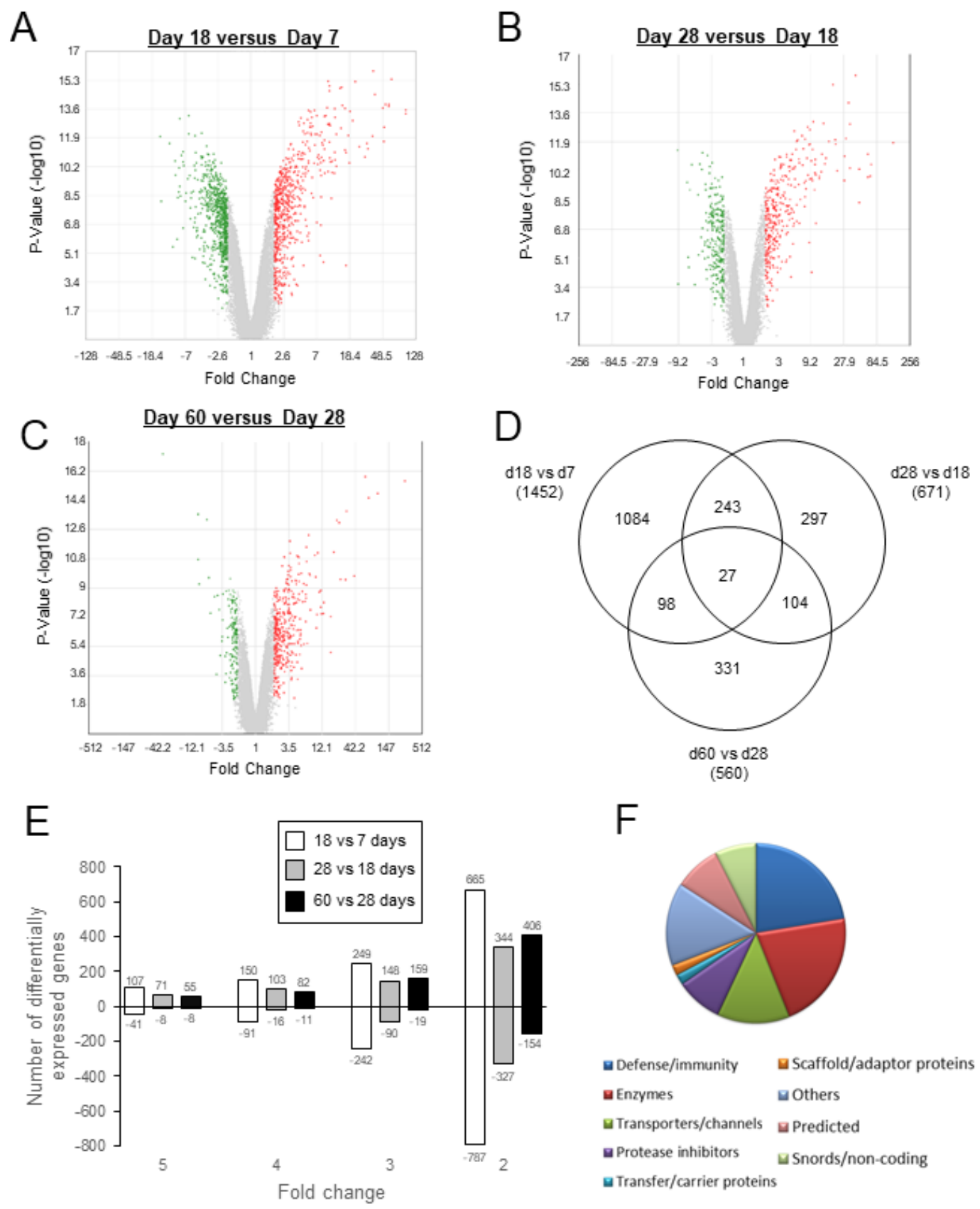

Figure 2 
Identification of enriched transcripts in the developing rat epididymis. Volcano plot comparing the transcriptome of 18-day old rats with the undifferentiated rat epididymis of 7-day old rats(A); 28 versus 18-day old rats (B); and 60 versus 28 day old rats (C). Red dots correspond to significantly up-regulated genes (fold-change $\nabla 2$ with a FDR adjusted $p$-value $\otimes 0.05$ ); green dots represent significantly downregulated genes (fold-change $\otimes 2$ with a FDR adjusted $P$ value $\otimes 0.05$ ); gray dots represent not significant gene probe sets. (D) Venn diagram representing the number of differentially regulated genes between different ages of epididymal development. Of the genes detected, 1084 were unique to changes between days 18 and 7, 297 between 28 and 18 and 331 between 60 and 28 days of age. Only 27 genes were differentially expressed in all datasets. (E) Number of genes that are significantly differentially expressed by 2-, 4-, and 5-fold in the epididymis between different developmental ages. (F) Classification of the 107 genes upregulated by more than 5 -fold between 18 and 7 days of age using PANTHER software. 
Day 18 versus Day 7
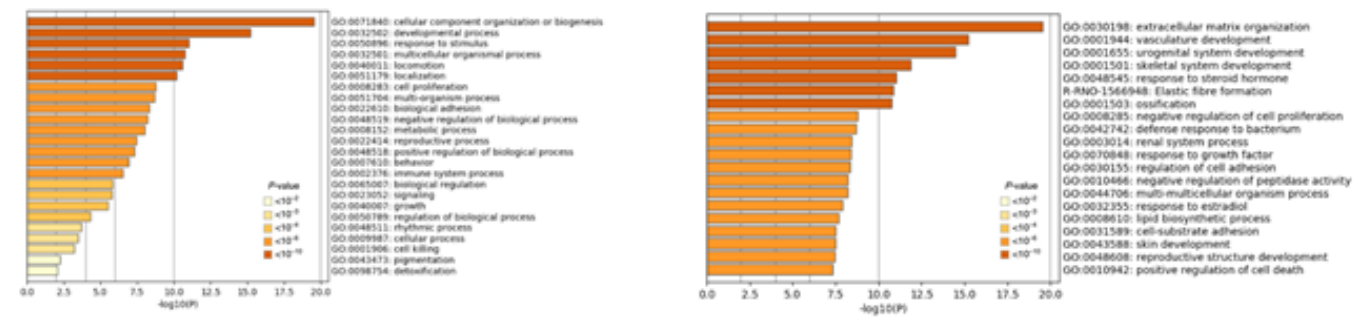

Day 28 versus Day 18
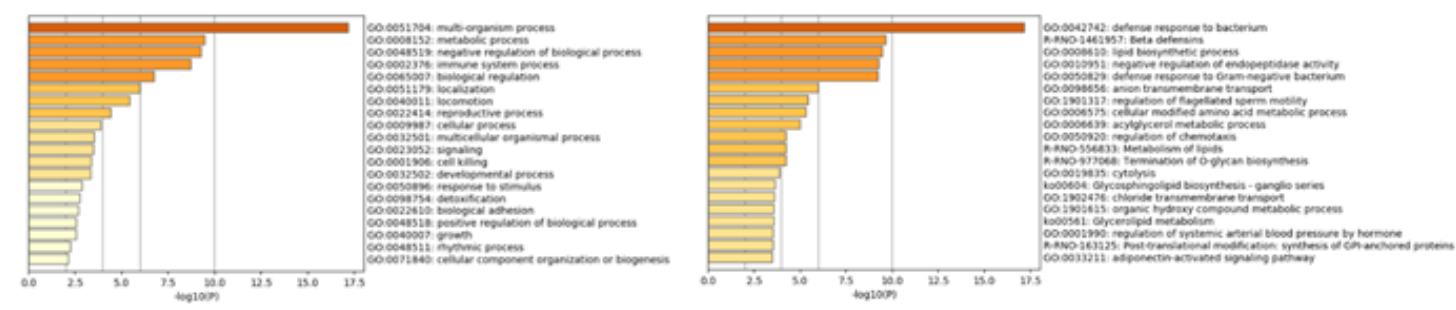

Day 60 versus Day 28
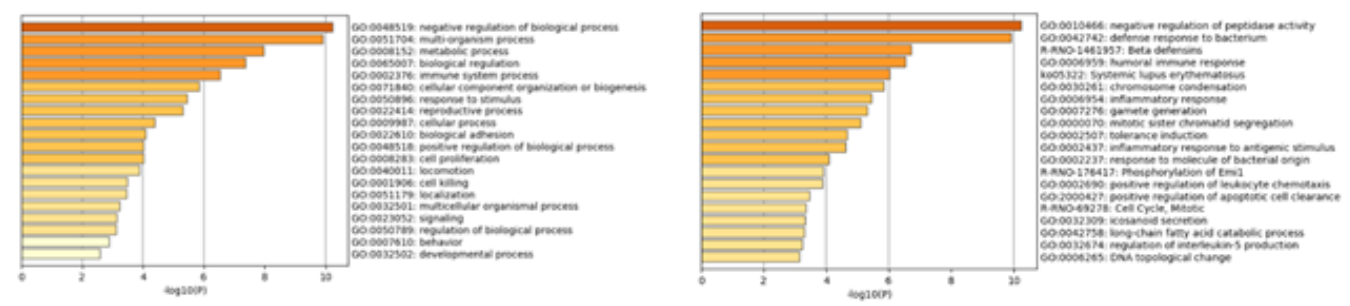

\section{Figure 3}

Enriched biological processes and cluster analyses of genes differentially expressed by a 2-fold change in the epididymides of rats at different developmental ages. Data were uploaded in Metascape and toplevel biological processes and top 20 enriched representative terms of clusters ( $p$-value $<0.01$, a minimum count of 3 , and an enrichment factor $>1.5$ ) were identified and presented. Colors represent the different $p$-values. 


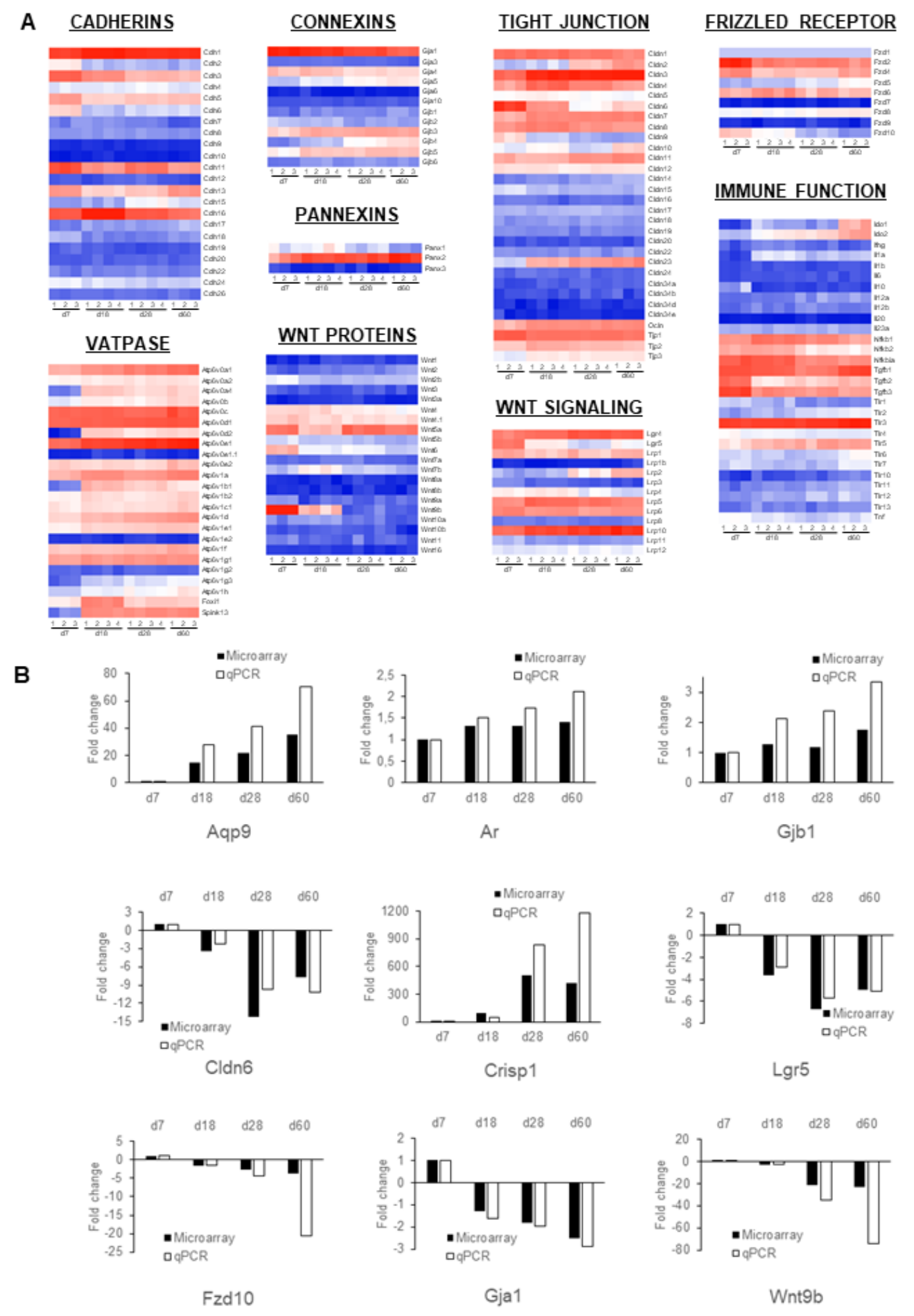

Figure 4

Families of genes expressed during development and validation of microarray data. (A) Heatmaps were generated using the Heatmapper software without any cutoff in gene expression levels or statistical tests. Heat maps of genes implicated in adherens junctions (cadherins), communication junctions 
(Connexins and Pannexins), tight junction proteins, Wnt signaling (Wnt proteins, WNT signaling, Frizzle receptors) V-ATPase and genes implicated in immune function are shown. (B) Validation of microarray results by real-time PCR analyses. mRNA levels of Aqp9, Androgen receptor (Ar), Gjb1, Cldn6, Crisp1, Lgr5, Fzd10, Gja1, and Wnt9b, in the 7-, 18-, 28-, and 60-day old rat epididymides were compared to levels found by microarray analyses. Levels of the selected genes were normalized to the expression level of the Atp5pb reference gene in each sample. Real-time PCR results are compared to the fold changes of microarray data. Data are expressed relative to 7-day.
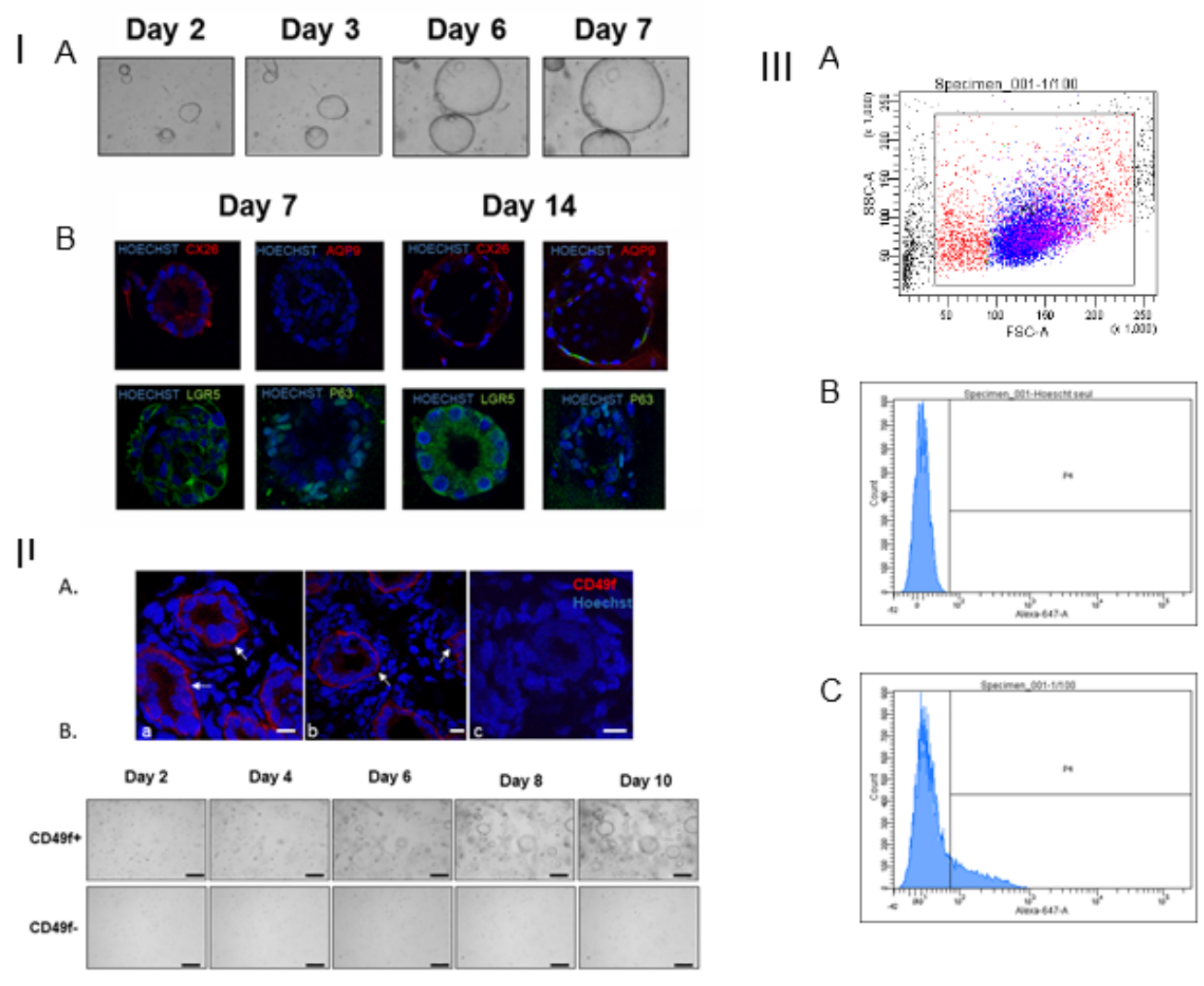


\section{Figure 5}

Derivation of organoids from dispersed single cells of epididymides from 7-day old rats. I. Cells from the epididymis were digested in collagenase and trypsin and cultured in Matrigel under 3D conditions. (A) Cells cultured for 2,3 6, and 7 days developed into large spherical organoids. (B) Cells expressed GJB2 and the stem cell marker LGR5, as well as p63, at 7 days of culture. By 14 days of culture, LGR5 staining was primarily cytoplasmic. AQP9, a marker of principal cells, was also present after 14 days. II. Selection of CD49f+ cells from epididymides of 7-day old rats. (A) Immunofluorescent staining of CD49f (red) in caput (a) and cauda (b) epididymides of 7-day old rats. CD49f was present at the basal and basolateral regions of the epididymal epithelium. The negative control, in which sections were incubated in absence of primary antibody, is shown in (c). Scale bar $=10 \mu \mathrm{m}$. (B) Magnetic separation of CD49f+ and CD49fcells from epididymides of 7-day old rats. Organoids were present only in CD49f+cells. Scale bar $=200$ $\mu \mathrm{m}$. III. Analysis of CD $49 \mathrm{f}+{ }^{\text {high }}$ and $\mathrm{CD} 49 \mathrm{f}+{ }^{\text {low }}$ cells in the epididymis of young rats. Cells from epididymides of 10-day old rats were incubated on ice for $30 \mathrm{~min}$ with a mouse monoclonal anti-rat Cd49f antibody conjugated with Alexa Fluor ${ }^{\circledR} 647$ and subjected to flow cytometric analyses. (A) Scatterplot analyses of total epididymal cells from 10-day old rats. Cells colored in blue were analyzed for fluorescent staining in B and C. (B) Histogram showing the fluorescence of the cells in the absence of the CD49f-Alexa Fluor 647 conjugated antibody. (C) Histogram showing the fluorescence of the cells incubated with the CD49f-Alexa Fluor 647 conjugated antibody. 


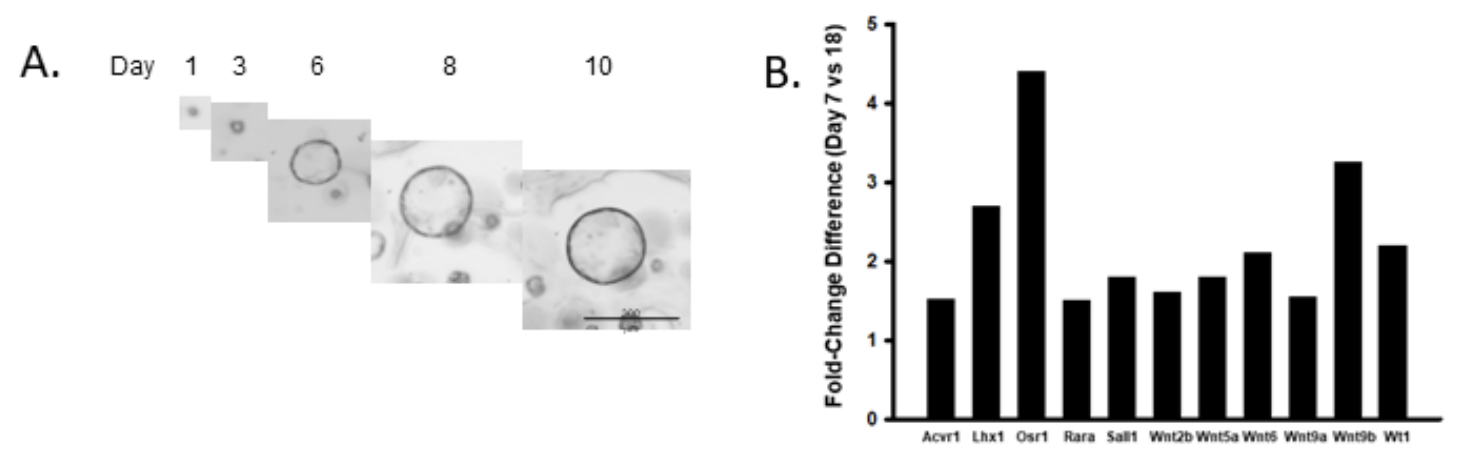

C. Day 6 Day 8 Day 10 Day 14

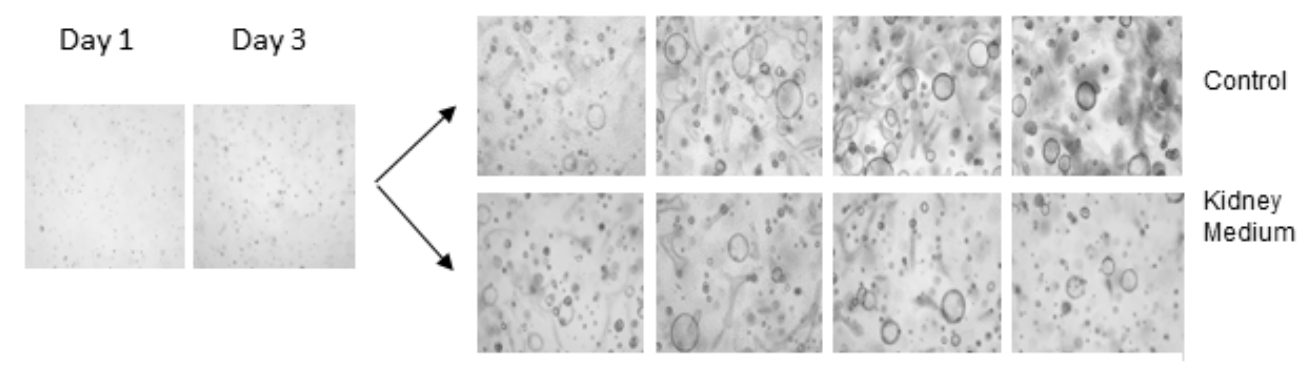

D.
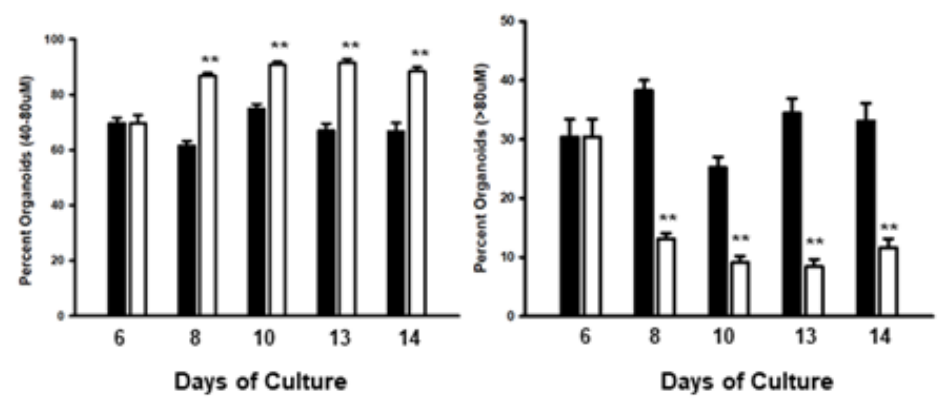

\section{Figure 6}

Organoids derived from CD49f+ cells. (A) Organoids derived from single CD49f ${ }^{+}$epididymal epithelial cells. cultured and followed over a 10-day period. (B) Expression of kidney differentiation markers present in epididymides of 7-day old rats versus day 18. (C) Culture of $\mathrm{CD}_{4} 9 \mathrm{f}^{+}$with either a control epididymal basal cell culture medium a commercial kidney stem cell medium. Quantification of the number of organoids according to size indicated that there was a significant increase in the number of organoids 
ranging between $40-80 \mu \mathrm{m}$ is size as well as a decrease in the number of organoids $>80 \mu \mathrm{m}$ in organoids grown in the commercial kidney medium. ${ }^{*} \mathrm{P}<0.05,{ }^{\star *} \mathrm{P}<0.01$.

A.

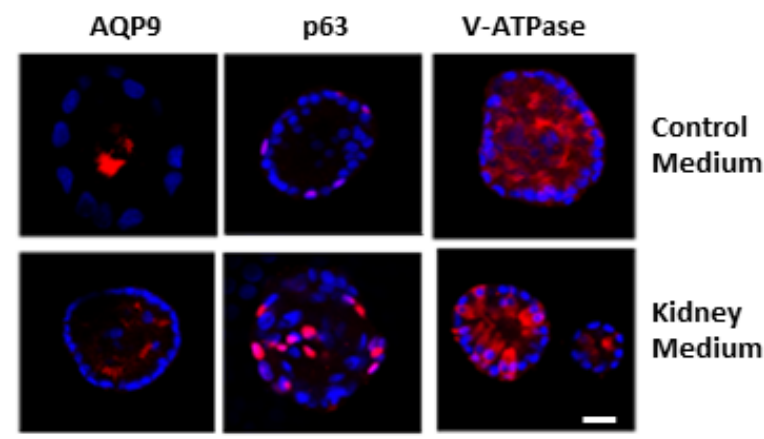

B.

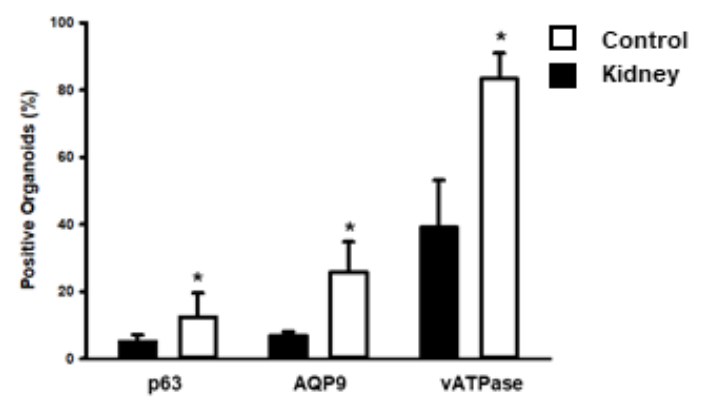

C.

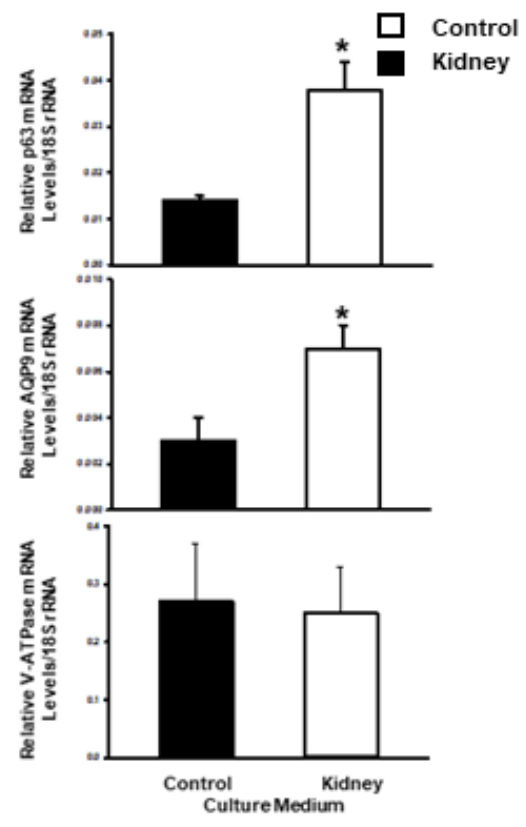

Figure 7

Differentiation of CD49f+ cell derived organoids. (A) Immunofluorescent staining of organoids derived from single CD49f+ epididymal columnar cells of 7-day old rats and cultured for 14 days. 
Immunostaining for p63, AQP9, and V-ATPase is shown in cells cultured in control epididymal basal cell medium versus the commercial kidney medium. (B) Quantification of p63, AQP9 and V-ATPase positive organoids. Data show a significant increase in immunostaining in organoids cultured in the commercial kidney medium. ${ }^{*}<<0.05$ (C) RT-PCR analyses of mRNA levels for $\mathrm{p} 63, \mathrm{AQP9}$ and V-ATPase in organoids cultured for 14 days in control epididymal basal cell medium versus the commercial kidney

medium. There was a significant increase in both p63 and AQP9 mRNA levels, while mRNA levels of the ATP6V1B2 isoform of V-ATPase was not different between culture media. ${ }^{*} P<0.05$.

\section{Supplementary Files}

This is a list of supplementary files associated with this preprint. Click to download.

- Tablel.pdf

- SupplTablel.pdf

- SupplTablell.pdf

- SupplTablelll.pdf

- SuppITableIV.pdf

- SupplTableV.pdf

- SupplTableVI.pdf 